\title{
Glycerol-3-phosphate acyltransferase-1 upregulation by O-GIcNAcylation of Sp1 protects against hypoxia- induced mouse embryonic stem cell apoptosis via mTOR activation
}

\author{
HJ Lee ${ }^{1}$, JM Ryu², YH Jung ${ }^{1}$, KH Lee ${ }^{1}$, DI Kim¹ and HJ Han,
}

Oxygen signaling is critical for stem cell regulation, and oxidative stress-induced stem cell apoptosis decreases the efficiency of stem cell therapy. Hypoxia activates 0 -linked $\beta$-N-acetyl glucosaminylation (O-GlcNAcylation) of stem cells, which contributes to regulation of cellular metabolism, as well as cell fate. Our study investigated the role of 0-GlcNAcylation via glucosamine in the protection of hypoxia-induced apoptosis of mouse embryonic stem cells (mESCs). Hypoxia increased mESCs apoptosis in a timedependent manner. Moreover, hypoxia also slightly increased the 0-GIcNAc level. Glucosamine treatment further enhanced the O-GIcNAc level and prevented hypoxia-induced mESC apoptosis, which was suppressed by 0-GIcNAc transferase inhibitors. In addition, hypoxia regulated several lipid metabolic enzymes, whereas glucosamine increased expression of glycerol-3-phosphate acyltransferase-1 (GPAT1), a lipid metabolic enzyme producing lysophosphatidic acid (LPA). In addition, glucosamine-increased 0-GIcNAcylation of Sp1, which subsequently leads to Sp1 nuclear translocation and GPAT1 expression. Silencing of GPAT1 by gpat1 siRNA transfection reduced glucosamine-mediated anti-apoptosis in mESCs and reduced mammalian target of rapamycin (mTOR) phosphorylation. Indeed, LPA prevented mESCs from undergoing hypoxia-induced apoptosis and increased phosphorylation of mTOR and its substrates (S6K1 and 4EBP1). Moreover, mTOR inactivation by rapamycin (mTOR inhibitor) increased pro-apoptotic proteins expressions and mESC apoptosis. Furthermore, transplantation of non-targeting siRNA and glucosamine-treated mESCs increased cell survival and inhibited flap necrosis in mouse skin flap model. Conversely, silencing of GPAT1 expression reversed those glucosamine effects. In conclusion, enhancing 0-GlcNAcylation of Sp1 by glucosamine stimulates GPAT1 expression, which leads to inhibition of hypoxia-induced mESC apoptosis via mTOR activation.

Cell Death and Disease (2016) 7, e2158; doi:10.1038/cddis.2015.410; published online 24 March 2016

Stem cells in the body are exposed to low oxygen pressure owing to the physiological distribution of vessels. ${ }^{1}$ This hypoxic niche for stem cells is essential to maintain the metabolic characteristics of stem cells. ${ }^{2}$ Thus, describing the oxygen nature of this stem cell niche is important for elucidating stem cell regulation. Oxygen signaling is a major determinant of cell fate-controlling cellular processes. Control of oxygen signaling in stem cells has the potential to regulate embryonic development, cell cultivation, cell reprogramming, and transplantation in regenerative medicine. ${ }^{1,3-6}$ There are many reports showing the effects of hypoxia on various kinds of stem cells, and it has been shown that hypoxia has a paradoxical role in stem cell behaviors and cell fate regulation related to stem cell type, ageing, and oxygen concentration. ${ }^{3,7-9}$ Studies of mechanisms by which stem cells function under hypoxia, and how they are regulated, have been undertaken. Several investigators recently reported that hypoxia-mediated stem cell metabolic alteration is associated with stem cell function; as a result, interest in the interaction between hypoxia and stem cell metabolism is growing. ${ }^{10,11}$ However, which metabolic factors are important for stem cell fate under hypoxia have not been elucidated.

$\mathrm{O}$-linked $\beta$-N-acetyl glucosaminylation (O-GlcNAcylation) is affected by cellular nutrient status and extra-cellular stresses including hypoxia. ${ }^{12-14}$ A hypoxia-induced glycolytic switch primarily stimulates hexosamine biosynthetic pathway (HBP) flux, which induces O-GlcNAcylation signaling. ${ }^{15} \mathrm{O}-\mathrm{GlcNAcy}-$ lation is catalyzed by O-linked $\mathrm{N}$-acetyl glucosamine transferase (OGT) to add $\mathrm{N}$-acetyl glucosamine to the serine or threonine residues of proteins. ${ }^{16-18}$ O-GlcNAcylation acts as an essential factor for controlling physiological processes including migration, proliferation, and survival in stem cells,

\footnotetext{
${ }^{1}$ Department of Veterinary Physiology, College of Veterinary Medicine, Research Institute for Veterinary Science and BK21 Creative Veterinary Research Center, Seoul National University, Seoul, Korea and ${ }^{2}$ Department of Veterinary Physiology, College of Veterinary Medicine, Chonnam National University, Gwangju 61186, Korea *Corresponding author: HJ Han, Department of Veterinary Physiology, College of Veterinary Medicine, Research Institute for Veterinary Science, Seoul National University, 151-741 Seoul, Korea. Tel: +82 2880 1261; Fax: +82 2880 2732; E-mail: hjhan@snu.ac.kr

Abbreviations: ACC1, acetyl-coenzyme A carboxylase 1; BrdU, bromodeoxyuridine; CPT1, carnitine palmitoyltransferase; ESC, embryonic stem cell; FASN, fatty acid synthase; GlcN, glucosamine; GPAT1, glycerol-3-phophate acyltransferase-1; HBP, hexosamine biosynthetic pathway; hMSCs, human mesenchymal stem cells; HRP, horseradish peroxidase; LPA, lysophosphatidic acid; LPAAT, Iysophosphatidic acid acyltransferase; MAGL, monoacylglycerol lipase; mESC, mouse embryonic stem cell; mTOR, mammalian target of rapamycin; N.S, not statistically significant; NT, non-targeting; GlcNAc, O-linked $\beta$-N-acetyl glucosaminylation; GlcNAc, N-acetyl D-glucosamine; OGT, O-linked N-acetyl glucosamine transferase; PI, propidium iodide; Ptx, pertussis toxin; PVDF, polyvinylidene fluoride; SCD1, stearoyl-CoA desaturase 1; siRNA, small interfering RNA; ROS, reactive oxygen species

Received 21.10.15; revised 10.12.15; accepted 14.12.15; Edited by S Lavandero
} 
and recently it was considered as a potential strategy for use in stem cell therapy. ${ }^{19-21}$ In addition, as many human metabolic diseases such as diabetes and cancer are attributed to aberrant O-GlcNAcylation, unraveling HBP-mediated O-GlcNAc signaling is important in the development of practical strategies for metabolic diseases treatment. For example, Liu et al. ${ }^{22}$ showed that glucosamine-mediated O-GlcNAcylation induced resistance to tissue damage resulting from ischemic injury and provided cardio-protection in an animal model. Furthermore, O-GlcNAcylation interacts with other nutrient metabolic pathways such as lipogenesis, gluconeogenesis, and glycogen synthesis. ${ }^{12,23,24}$ Among these metabolic pathways, lipid metabolism is reported to have a central role in controlling stem cell fate. ${ }^{25,26}$ Collectively, these results suggest that O-GIcNAcylation can be a useful tool for use in cellular metabolic regulation, and identification of an O-GIcNAcylation-regulating potential lipid metabolic factor, which is important for stem cell regulation, may suggest potentially useful metabolic approach in stem cell therapy.

Embryonic stem cells (ESCs) are distinctive in that they have a self-renewal capacity, exhibit pluripotency to enable differentiation into cellular derivatives of three lineages, and may be used as a representative in vitro model in the study of early embryo development, pluripotent stem cell physiology, and clinical applications. ${ }^{27-29}$ Despite the clinical limitation associated with ESCs and the possibility of cancer formation, several studies into the therapeutic effects of ESCs in regenerative medicine have been reported. Indeed, administrations of human or mouse ESCs (mESCs) has induced a paracrine effect and improved damaged cell functions. ${ }^{30-32}$ However, despite the benefit of ESCs in regenerative medicine, ESC apoptosis remains an impediment to ESC applications using hypoxia. ${ }^{33-35}$ Thus, researchers are investigating ways to minimize ESC apoptosis and control ESC fate under hypoxia. In this study, we used glucosamine to induce $\mathrm{O}-$ GlcNAcylation. Therefore, our study investigated the role of $\mathrm{O}-$ GlcNAcylation via glucosamine (GlcN) which is recognized as a HBP activator ${ }^{36}$ in lipid metabolism and in protection of mESC apoptosis under hypoxia.

\section{Results}

Effect of O-GIcNAcylation on mESC survival under hypoxia. To examine the effect of hypoxia on mESCs survival, mESCs were incubated under hypoxic condition for various durations $(0-72 \mathrm{~h})$. Anti-apoptotic protein $\mathrm{Bcl}-2$ expression level decreased in a time-dependent manner after $12 \mathrm{~h}$ of hypoxia. But, hypoxia increased expression levels of Bax, cleaved caspase-9, and cleaved caspase-3 after $12 \mathrm{~h}$ of hypoxia (Figure 1a). Viability of hypoxia-treated cells decreased in a time-dependent manner and was significantly lower than that of control cells during 24-72 $\mathrm{h}$ of hypoxia treatment (Figure 1b). To investigate the effect of hypoxia on intracellular ROS production of mESCs, we performed DCFDA staining assays. Intracellular ROS production in $\mathrm{mESCs}$ under hypoxia for $24 \mathrm{~h}$ increased to $156 \%$ of that in the normoxia control (Figure 1c). To confirm the role of glucosamine on O-GIcNAcylation in mESCs, we used RL-2 antibody specific for O-GlcNAc. Hypoxia treatment for $24 \mathrm{~h}$ slightly increased total O-GIcNAc level, and the maximum increase in O-GIcNAc level was observed in cells treated with $10 \mu \mathrm{M}$ of glucosamine and hypoxia (Figure 1d). As shown in Figure 1e, the effect of another O-GlcNAcylation activator GlcNAc was also similar to that of glucosamine. To determine the effect of glucosamine on mESC survival, we examined cell viability after $24 \mathrm{~h}$ of hypoxic incubation with various concentrations of the glucosamine (10 mM to $1 \mu \mathrm{M})$. Hypoxia significantly decreased cell viability, but viability was recovered by $10 \mu \mathrm{M}$ of glucosamine treatment (Figure 2a). In addition, hypoxia decreased Bcl-2 expression, and increased Bax, cleaved caspase-9, and cleaved caspase-3 expressions, which were reversed by glucosamine treatment (Figure 2b). Live-cell imaging results showed that the size of mESC colonies with glucosamine under hypoxia was significantly larger than that of the hypoxia controls during 24-48 h incubation (Figure 2c). Next, we investigated whether glucosamine-induced O-GlcNAcylation regulated mESC survival under hypoxia. Addition of the OGT inhibitor ST045849 decreased the previous glucosamine-increased cell viability (Figure $2 \mathrm{~d}$ ). Consistent with this result, the glucosamine treatment reduced annexin V-positive and PI-positive mESCs under hypoxia, which was significantly inhibited by ST045849 addition (Figure 2e).

\section{Effect of O-GIcNAcylation of Sp1 on GPAT1 expression.} To determine the effect of hypoxia and glucosamine on lipid metabolic enzyme expressions in mESCs, we assessed mRNA expression levels of fatty acid synthase (fasn), acetylcoenzyme A carboxylase 1 (acc1), carnitine palmitoyltransferase 1a (cpt1a), cpt1b, monoacylglycerol lipase (magl), gpat1, gpat2, gpat3, gpat4, stearoyl-CoA desaturase 1 (scd1), scd2, scd3, scd4, lysophosphatidic acid acyltransfer-

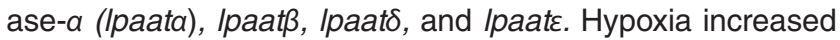
the mRNA expression levels of gpat1, scd1, Ipaata, Ipaat $\delta$, and $I p a a t \varepsilon$, whereas glucosamine treatment increased only gpat1 mRNA expression (Figure 3a). Immunofluorescence staining results showed a $210 \%$ increase in the fluorescence intensity of GPAT1 in the glucosamine and hypoxia-treated mESCs and a $137 \%$ increase in the fluorescence intensity of GPAT1 in hypoxia-treated mESCs (Figure 3b). Furthermore, glucosamine-induced GPAT1 expression was inhibited by ST045849 pretreatment (Figure 3c). However, tunicamycin, a $\mathrm{N}$-linked glycosylation inhibitor, did not affect glucosamineinduced GPAT1 expression of mESCs under hypoxia (Supplementary Figure S1). As shown in Figures 3d and e, hypoxia and glucosamine stimulated O-GlcNAcylation and nuclear translocation of Sp1. Nuclear translocation of Sp1 was regulated by the addition of ST045849 and the OGA inhibitor PUGNAc. After $24 \mathrm{~h}$ of hypoxia and hypoxia with glucosamine treatments, fluorescence intensity of Sp1 in the Pl-stained region increased to $129 \%$ and $193 \%$, respectively. However, total fluorescence intensity of Sp1 was not affected by hypoxia and glucosamine treatment (Figure 3f). In addition, pretreatment with the Sp1 inhibitor mithramycin $A$ $(1 \mu \mathrm{M})$ suppressed glucosamine-induced GPAT1 expression (Figure $3 \mathrm{~g}$ ). However, the inhibition of SREBP1 activity by fatostatin pretreatment did not affect glucosamine-induced GPAT1 expression (Supplementary Figure S2). On the basis 
a
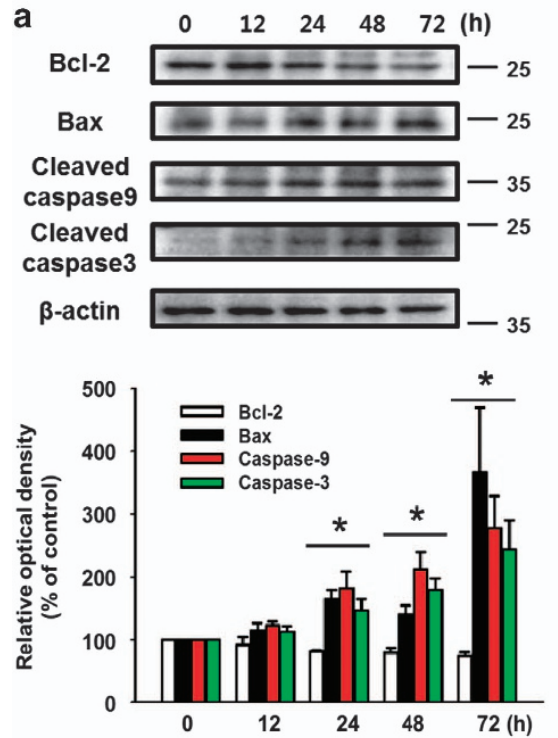

b

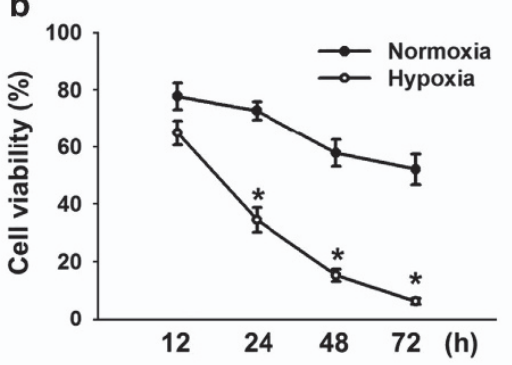

d
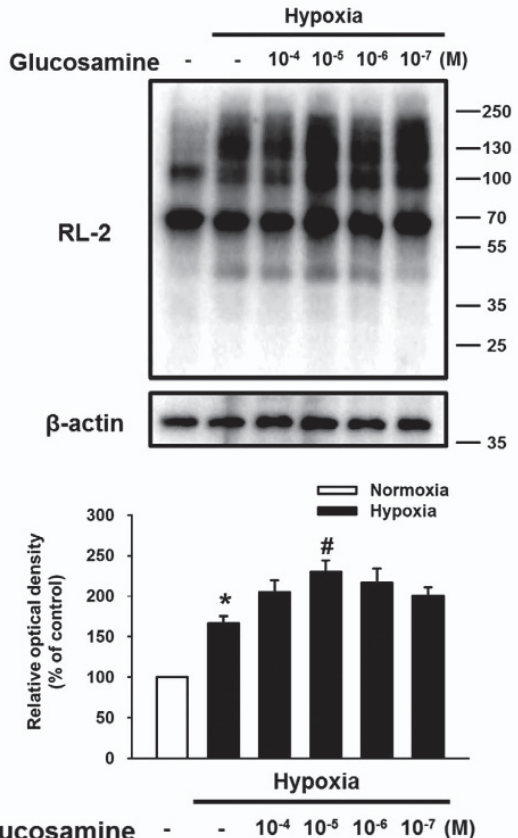

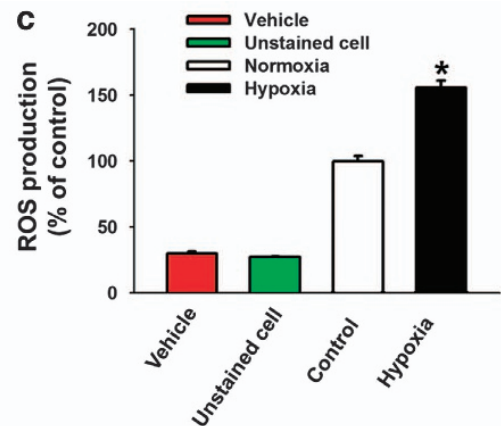

e GICNAC - $\quad 10^{-4} 10^{-5} 10^{-6} 10^{-7}$ (M)

RL-2
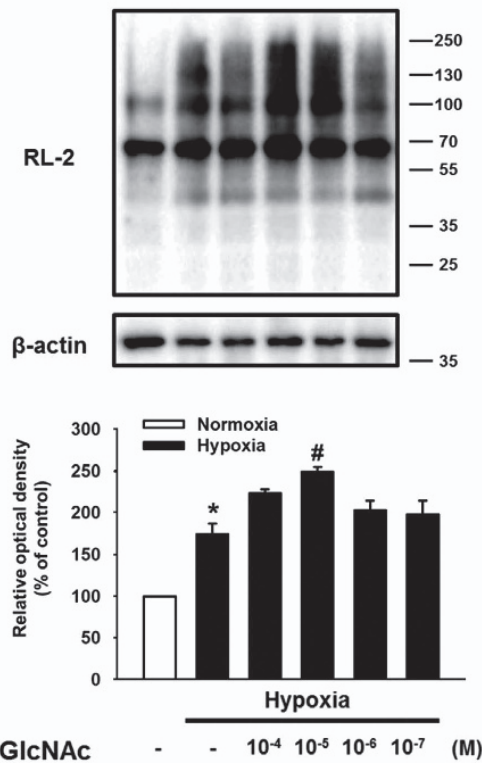

Figure 1 Effects of hypoxia and glucosamine on mouse embryonic stem cells apoptosis. (a) Cells were exposed to hypoxic condition for 0-72 h. Bcl-2, Bax, cleaved caspase9, and cleaved caspase-3 proteins were detected by western blotting. Each result shown is representative of three independent experiments. (b) Cell viability was measured directly using a Petroff-Hausser counting chamber (Hausser Scientific, Horsham, PA, USA). Data are reported as mean \pm S.E.M. of three independent experiments with duplex dishes. ${ }^{*} P<0.05$ versus normoxia control. (c) Cells were exposed to hypoxia for $24 \mathrm{~h}$, and then DCF-DA-sensitive cellular ROS was measured by using luminometer. Data are reported as mean \pm S.E.M. of two independent experiments with triple dishes. ${ }^{*} P<0.05$ versus normoxia control. (d, e) Cells were treated with various concentrations of glucosamine (GICN) and GIcNAc $\left(10^{-4}\right.$ to $\left.10^{-7} \mathrm{M}\right)$ for $30 \mathrm{~min}$ before hypoxia treatment. Glucosamine-pretreated cells were exposed to hypoxia for $24 \mathrm{~h}$; and then, RL-2 and $\beta$ actin were detected by using western blotting. Each result shown is representative of three independent experiments

of these results, we suggest that O-GlcNAcylation has a critical role in glucosamine-induced Sp1 nuclear translocation, which is followed by regulation of GPAT1 expression in mESCs under hypoxia.

Role of GPAT1 in mTOR activation and mESC apoptosis under hypoxia. Next, to determine the effect of lipid metabolic enzymes' metabolites on mESC survival under hypoxia, we performed cell viability assays after mESC pretreatment with palmitic acid, oleic acid, and LPA. As shown in Figure $4 \mathrm{a}$, the survival effect of LPA was stronger than that of other substrates in mESCs under normoxia or hypoxia. Subsequently, we treated mESCs with glucosamine and gpat1-specific siRNA to assess the role of GPAT1 on mESC survival under hypoxia. Silencing of GPAT1 expression decreased $\mathrm{Bcl}-2$ expression, but increased Bax, cleaved caspase-9, and cleaved caspase-3 expressions (Figure 4b). We performed trypan blue exclusion cell viability assays and annexin V/PI FACS analysis to elucidate further the role of GPAT1. The cell viability of gpat1 siRNA with glucosamine pretreatment was similar to that of hypoxia-treated mESCs (Figures 4c and d). In addition, hypoxia and glucosamineinduced GPAT1 did not affect undifferentiation markers Oct3/4 and nanog expressions (Supplementary Figure S3). These results indicate that glucosamine-induced GPAT1 upregulation in hypoxia significantly affects mESC survival. Subsequently, we investigated the detailed signaling pathway by which GPAT1 induces mESC survival under hypoxia. As shown in Figure 5a, glucosamine treatment phosphorylated mTOR, which was blocked by gpat1 siRNA transfection. We confirmed that glucosamine treatment increased Bcl-2 expression, and decreased Bax, cleaved caspase- 9 
a

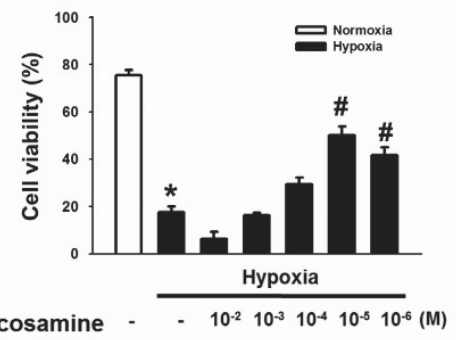

b

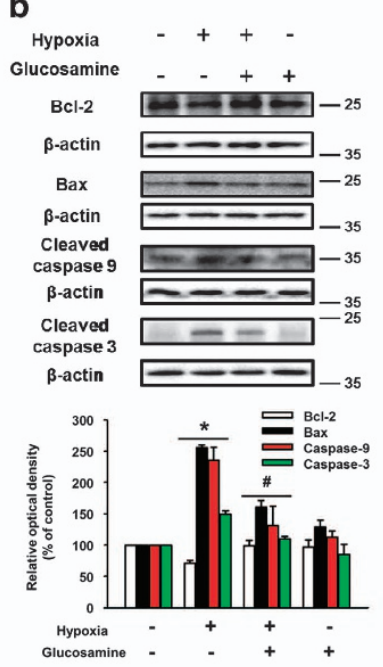

C
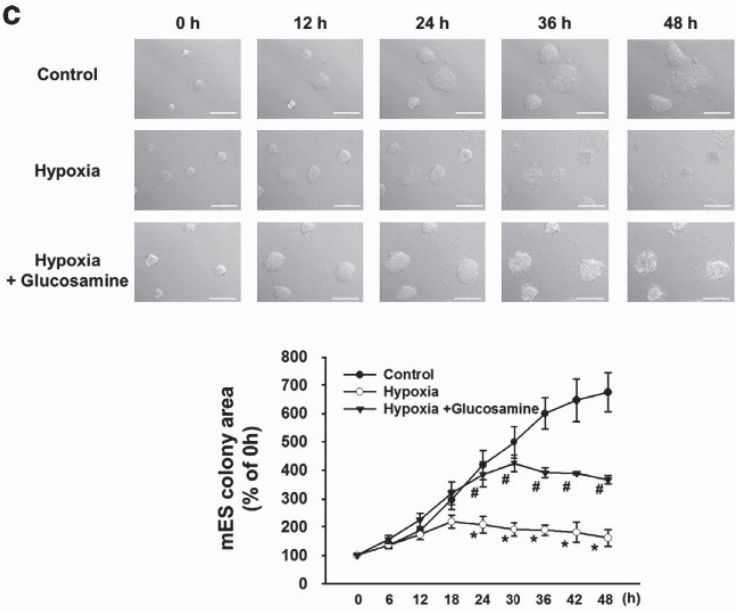

d

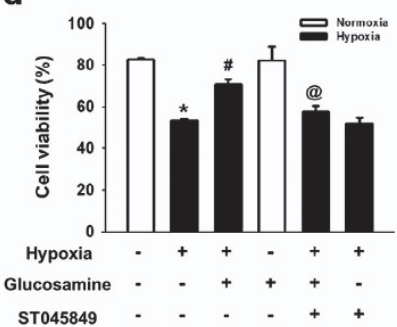

e

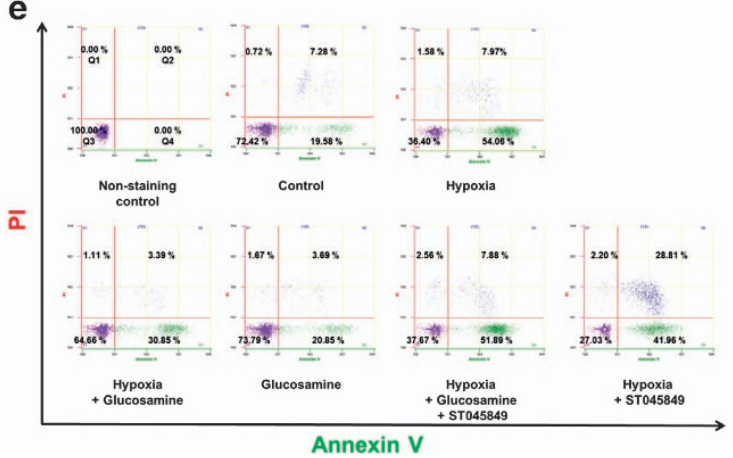

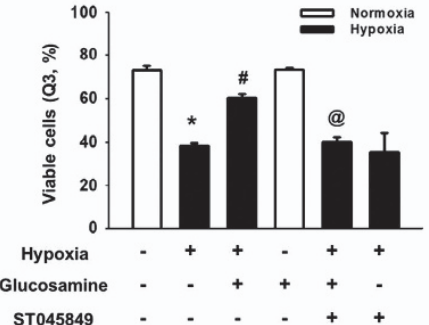

Figure 2 Effect of glucosamine-induced O-GlcNAcylation on mouse embryonic stem cells apoptosis. (a) Cells were pretreated with various concentrations of glucosamine $(\mathrm{GlcN}, 100 \mathrm{mM}$ to $1 \mu \mathrm{M})$; and then, exposed to hypoxia for $24 \mathrm{~h}$. Cell viability was detected using by trypan blue exlusion cell viability assay. Data are reported as mean \pm S.E.M. of two independent experiments with triple dishes. $n=6,{ }^{*} P<0.05$ versus normoxia control. (b) Cells were pretreated with glucosamine (10 $\left.\mu \mathrm{M}\right)$ for 30 min before hypoxia treatment. After $24 \mathrm{~h}$ of hypoxic incubation, Bcl-2, Bax, cleaved caspase-9, cleaved caspase-3, and $\beta$-actin proteins were detected by western blotting. Each result shown is representative of three independent experiments. (c) mESCs colony size was acquired by using live-cell imaging microscopy system. Cells were exposured to normoxic and hypoxic conditions for $48 \mathrm{~h}$. Data are analyzed by using ImageJ software. Scale bars $=100 \mu \mathrm{m}$ (magnification $\times 200$ ). Each sample is representative of three independent experiments. ${ }^{*} P<0.05$ versus control, and ${ }^{\#} P<0.05$ versus hypoxia treatment alone. (d) Cells were pretreated ST045849 $(20 \mu \mathrm{M})$ for 30 min before treatment of glucosamine $(10 \mu \mathrm{M})$ for $30 \mathrm{~min}$. Subsequently, cells were exposed to hypoxia for $24 \mathrm{~h}$. Cell viability were measured directly using a Petroff-Hausser cell counting chamber. Error bars are reported as mean \pm S.E.M. of three independent experiments with duplex dishes. $n=6,{ }^{\star} P<0.05$ versus control, ${ }^{\sharp} P<0.05$ versus hypoxia treatment alone, and ${ }^{\circledR} P<0.05$ versus hypoxia with glucosamine. (e) Cells were immunostained with FITC-conjugated annexin V antibody and PI, and analyzed by flow cytometry. Annexin V-negative-PInegative cells (Q3) were considered viable, annexin V-negative-PI-positive cells (Q1) were considered necrotic, annexin V-positive-PI-positive cells (Q2) were considered late apoptotic, and annexin V positive-PI-negative cells (Q4) were considered early apoptotic. Data are presented as a mean \pm S.E.M. of two independent duplex dishes. ${ }^{*} P<0.05$ versus control, ${ }^{\#} P<0.05$ versus hypoxia treatment alone, and ${ }^{\circledR} P<0.05$ versus hypoxia with glucosamine

expressions and cytochrome $\mathrm{c}$ release, which were reversed by $10 \mathrm{nM}$ of mTOR inhibitor rapamycin pretreatment (Figures $5 \mathrm{~b}$ and $\mathrm{c}$ ). In addition, glucosamine treatment increased $\left[{ }^{3} \mathrm{H}\right]$-thymidine incorporation level of mESCs under hypoxia, which was blocked by rapamycin addition (Supplementary Figure S4). Next, we treated LPA to determine the role of GPAT1 metabolite in mESC apoptosis under hypoxia. We examined cell viability after $24 \mathrm{~h}$ of hypoxic incubation with various concentrations of LPA $(1 \mu \mathrm{M}$ to $1 \mathrm{nM}$ ). The $1 \mu \mathrm{M}$ and $0.1 \mu \mathrm{M}$ LPA pretreatments significantly increased the cell viability of mESCs under hypoxia (Figure $5 \mathrm{~d}$ ). In addition, hypoxia and hypoxia with $1 \mu \mathrm{M}$ of LPA pretreatments increased phosphorylation of MTOR and mTOR substrates (S6K1 and 4EBP1). The LPA-induced phosphorylation of mTOR and mTOR substrates were suppressed by pretreatment with the LPA receptor inhibitor Ptx (Figure 5e). After hypoxia and hypoxia with LPA treatment, the fluorescence intensity of $p$-mTOR in mESC colonies increased to $187 \%$ and $342 \%$, respectively (Figure 5f). To elucidate the role of mTOR in mESC survival under hypoxia, we assessed expression levels in apoptosisrelated proteins. Treatment with LPA increased Bcl-2 expression and decreased Bax, cleaved caspase-9, and cleaved caspase-3 expressions, which were reversed by rapamycin addition (Figure $5 \mathrm{~g}$ ). Cell viability assay and annexin V/PI FACS analysis results showed that rapamycin treatment reduced LPA-induced mESC survival (Figures $5 \mathrm{~h}$ and i). In addition, we performed several experiments to identify the role of NF-KB in mESC apoptosis under hypoxia. We found that LPA treatment increased phosphorylation (Ser 536) of 
$\mathrm{NF}-\kappa \mathrm{B}$, the activation marker (Supplementary Figure S5). However, NF- $k$ B inhibitor SN-50 did not affect LPA-induced survival effect on mESCs under hypoxia (Supplementary Figure S6). On the basis of these results, we suggest that LPA activates the mTOR pathway, resulting in mESC survival under hypoxia.

Role of GPAT1 on mESC survival and skin flap survival. We performed mouse skin flap surgery to test the protective roles of glucosamine and GPAT1 on transplanted mESC survival. Twelve days after surgery, an extended necrotic area in the central and distal part of the flap appeared in the vehicle, glucosamine, and LPA alone control groups. The necrotic area of the NT siRNA-transfected mESCs alone group was smaller than that of vehicle group. The necrotic region in the skin flap was reduced to a significantly greater extent in NT siRNA-transfected mESCs with either glucosamine or LPA treatment than that in the NT siRNA-transfected mESCs alone group. However, the necrotic area of the gpat1 siRNA-transfected mESCs with glucosamine treatment group was larger than that of the NT siRNA-transfected mESCs with glucosamine treatment group (Figure 6b). Histological evaluation, via $H \& E$ staining, showed an intact epithelial layer in the NT siRNA-transfected mESCs with glucosamine or LPA treatments, which indicates that mESCs with glucosamine treatment can stimulate skin flap survival under ischemic conditions (Figure 6c). Immunohistochemistry results showed that glucosamine and LPA significantly increased the number of BrdU-positive mESCs in the skin flap. The number of gpat1 siRNA-transfected mESCs in the glucosamine treatment group was similar to that in the NT siRNA-transfected mESCs alone group (Figure 6d).

\section{Discussion}

The results of the present investigation demonstrate the role of GPAT1 expression via augmented O-GIcNAcylation in mESC survival under hypoxia. Although the effect of hypoxia on stem cell survival is not fully elucidated, ${ }^{3,4}$ we observed that increasing the exposure of mESC to hypoxia resulted in duration-dependent apoptosis. Mishra et al. ${ }^{37}$ reported that an increase in the $\mathrm{Bax} / \mathrm{Bcl}-2$ ratio is essential for caspase- 9 mediated mitochondrial apoptosis under hypoxia. In this study, hypoxia and glucosamine treatments increased O-GlcNAc level, and glucosamine-augmented O-GlcNAcylation suppressed hypoxia-induced mESC apoptosis. In support of our results, there are several reports that glucosamine activates HBP flux and has a protective role via O-GlcNAcylation in other types of cells including cardiomyocytes and retinocytes. ${ }^{36,38,39}$ Moreover, our previous study established that glucosamine induces OGT expression, which is followed by an increase in O-GlcNAc levels in mESCs. ${ }^{40}$ However, a high dose $(>1 \mathrm{mM}$ ) of glucosamine did not induce the mESC protective effect. There are several reports showing that a high level of glucosamine-induced HBP activation generates excess ROS, leading to apoptosis. ${ }^{41,42}$ In addition, there are several reports suggesting that O-GIcNAc signaling contributes to undifferentiation and self-renewal. ${ }^{43,44}$ Furthermore, several reports suggest that hypoxia-induced O-GIcNAc signaling regulates metabolic alteration as well as survival responses against noxious stimuli in stem cells. ${ }^{45-47}$ These results indicate the need to clarify the interaction of O-GIcNAc signaling-mediated cell survival with metabolic alteration. Based upon current and past results, we suggest that $\mathrm{O}-$ GlcNAcylation is a key factor in maintaining of stem cell populations in vivo.

There are several recent reports on the interaction between lipid metabolic alteration by hypoxia and stem cell regulation. Indeed, several researchers have reported that hypoxia modulates lipid metabolic processes including fatty acid synthesis and $\beta$-oxidation. ${ }^{48,49}$ Our present study shows that hypoxia increased levels of metabolic enzymes that contribute to fatty acid and bio-lipid metabolite production and phosphatidic acid signaling. These lipid metabolites have been reported to have the ability to control stem cell functions such as migration, proliferation, and survival. ${ }^{50-52}$ In addition, alteration of lipid metabolic enzymes profiles by hypoxia appears stem cell type-specific. Our previous paper reported that hypoxia predominantly increased FASN in human mesenchymal stem cells (hMSCs), which regulates hMSC proliferation and migration. ${ }^{11}$ Ben-David et al. ${ }^{50}$ reported that SCD1 inhibition eliminated undifferentiated human ESCs selectively, but our previous study showed that SCD1 inhibition did not affect hMSC proliferation. Taken together, these results indicate a difference in lipid sensitivity between stem cell types. In particular, it is noteworthy that glucosamine up-regulates GPAT1 expression through O-GlcNAcylation, which has an important role in $\mathrm{mESC}$ survival under hypoxia. GPAT1 is a lipid metabolic enzyme localized at the mitochondrial outer membrane and is a major form of four GPAT isotypes. ${ }^{53,54}$ GPAT1 metabolizes glycerol-3-phosphate with long chain fatty acyl-CoA to form LPA. ${ }^{55}$ Although no reports have demonstrated a role of GPAT1 in stem cells, several investigators have reported that GPAT1 is a factor potentially controlling various cellular processes such as lipid metabolism, mitochondrial dynamics, apoptosis, and proliferation in other cell types. ${ }^{56-58}$ Further investigation into GPAT1's effect and the detailed mechanism for that effect in stem cells will provide information important for stem cell regulation. As Sp1 is emerging as a potential therapeutic target in metabolic diseases, interest in its effect on metabolic and nutritional regulation is increasing. ${ }^{59-61}$ Furthermore, Sp1 is a transcription factor binding to the human GPAT1 promoter and regulating gene expression. ${ }^{55,62}$ In addition, there are several reports suggesting that a HBP flux-mediated protective effect is induced via O-GlcNAcylation of specific proteins. ${ }^{63,64}$ Moreover, O-GlcNAcylation of Sp1 is important for its subcellular localization, stabilization, and transcriptional regulation. ${ }^{60,65,66}$ Taken together, these findings indicate that $\mathrm{Sp} 1$ regulation by O-GIcNAcylation can be a practical approach to metabolic regulation of stem cell fate.

Furthermore, our results demonstrate that O-GlcNAcylation-mediated GPAT1 expression significantly suppresses hypoxia-induced mESC mitochondrial apoptosis and increases proliferation via mTOR activation, which may suggest that glucosamine-induced resistance against hypoxia is attributed to GPAT1 signaling-mediated mTOR activation. The GPAT1 metabolite LPA has been reported as a potential bioactive lipid molecule that can modulate stem cell function. ${ }^{67-70}$ You et al. ${ }^{71}$ reported that LPA activates 
the mTOR pathway via an LPA receptor-mediated ERK activation pathway. In addition, there are reports that $\mathrm{mTOR}$ is a nutrient-sensing molecule and can regulate stem cell survival. ${ }^{72-74}$ A previous study reported that AKT/mTOR pathway activation increased the expression of antiapoptotic proteins $\mathrm{Bcl}-2$ and $\mathrm{Bcl}-\mathrm{xL}$, resulting in cell survival and growth. This result suggests that there may be an interaction between GPAT1 signaling-mediated mTOR activation and apoptosis-related protein expression. ${ }^{75}$ In this study we demonstrate that glucosamine-induced GPAT1 expression increased mESC survival after transplantation; moreover, it prevented ischemia-induced flap necrosis in vivo in an animal model. The effects of glucosamine and GPAT1 on transplanted stem cell survival demonstrated in this study

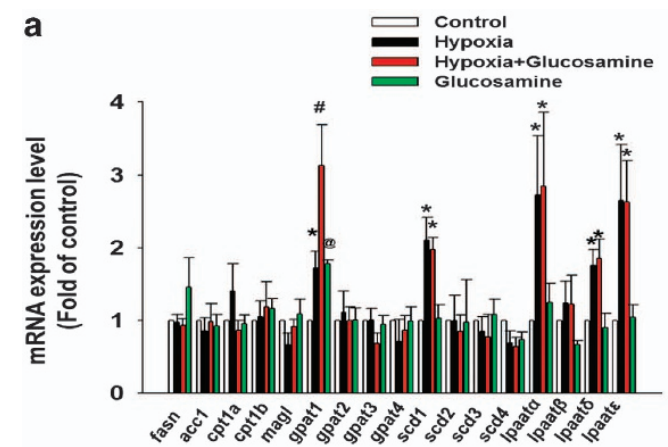

b
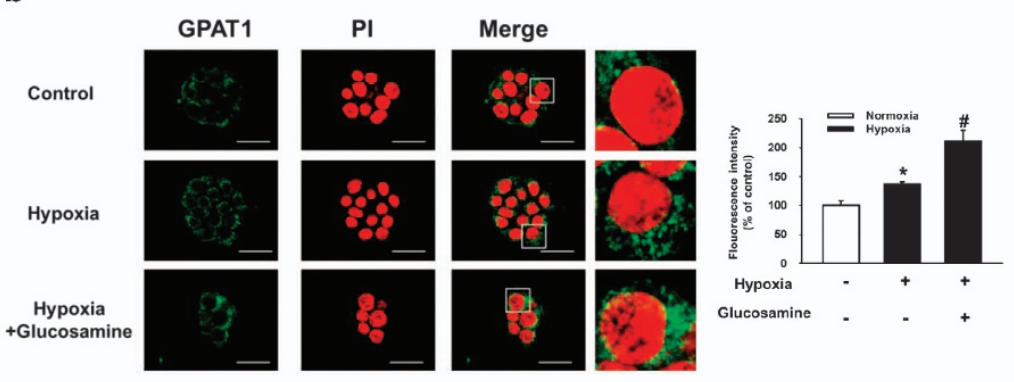

C

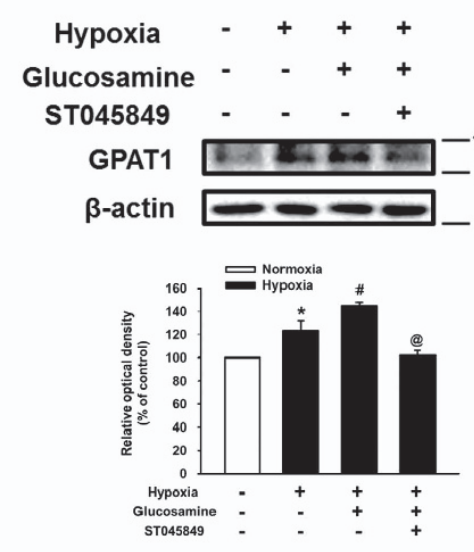

d
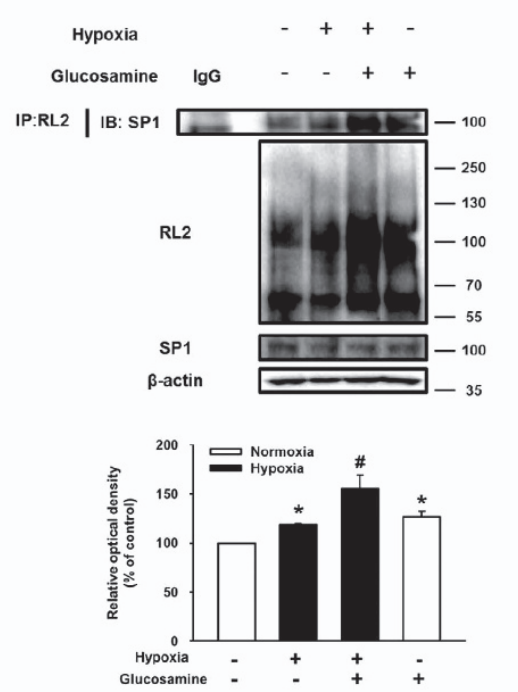

e
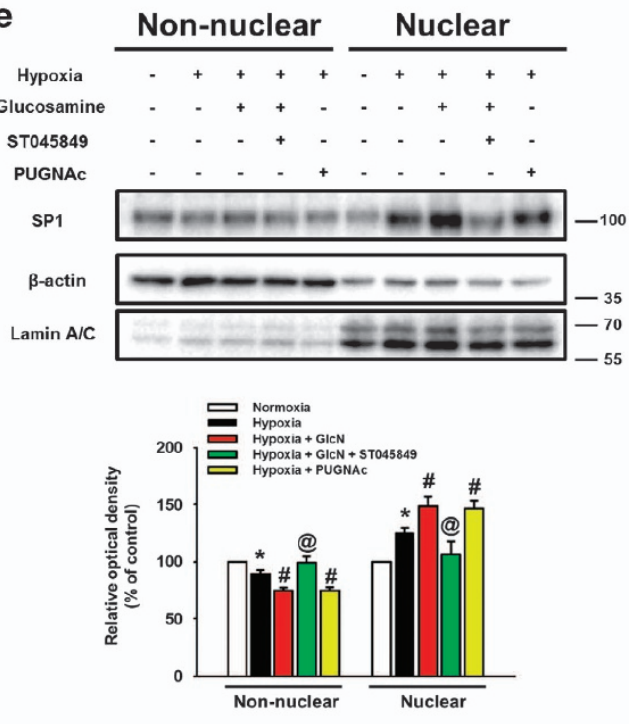

$\mathbf{f}$
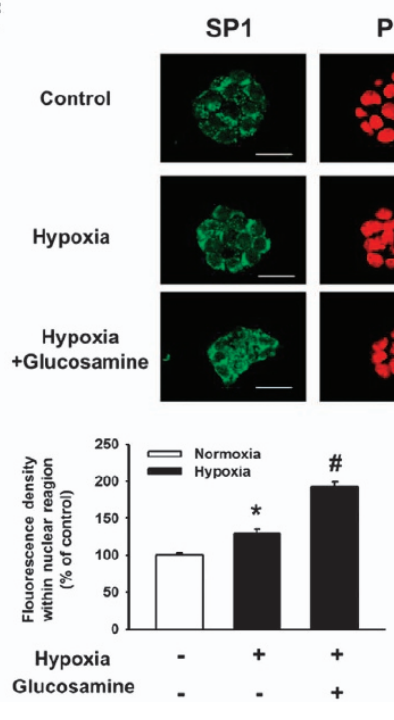
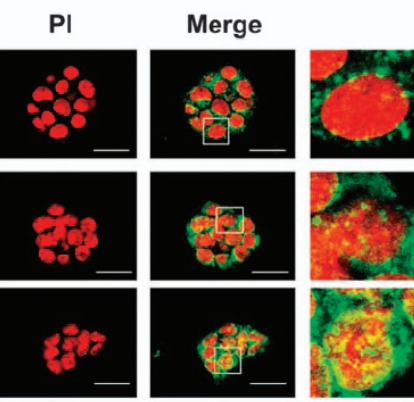

ב

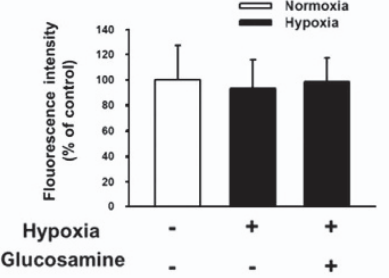

g

Hypoxia

Glucosamine

Mithramycin A
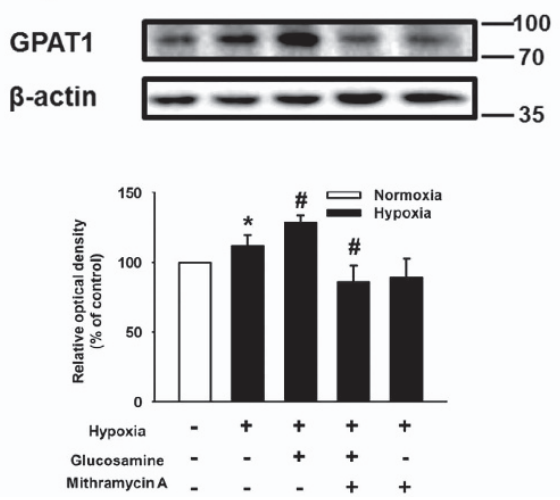
a

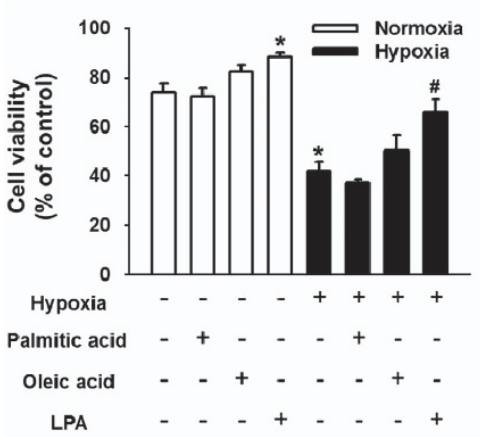

b

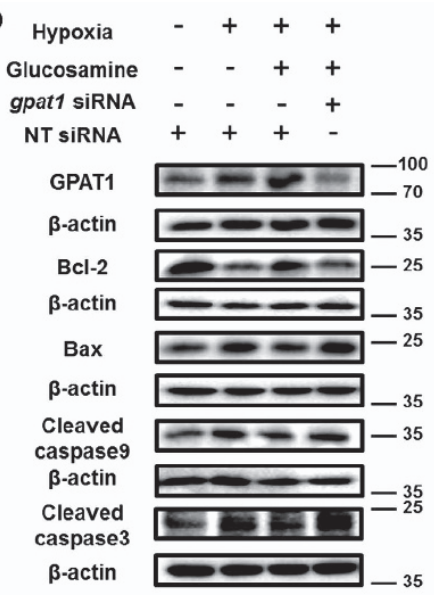

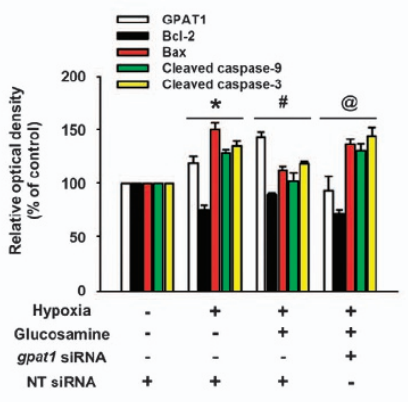

c

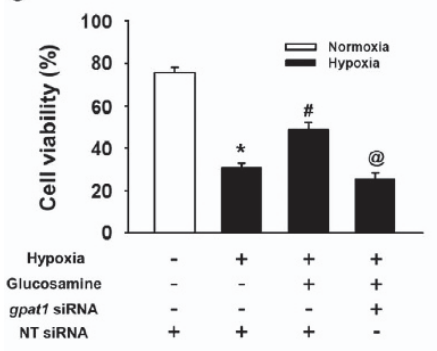

d

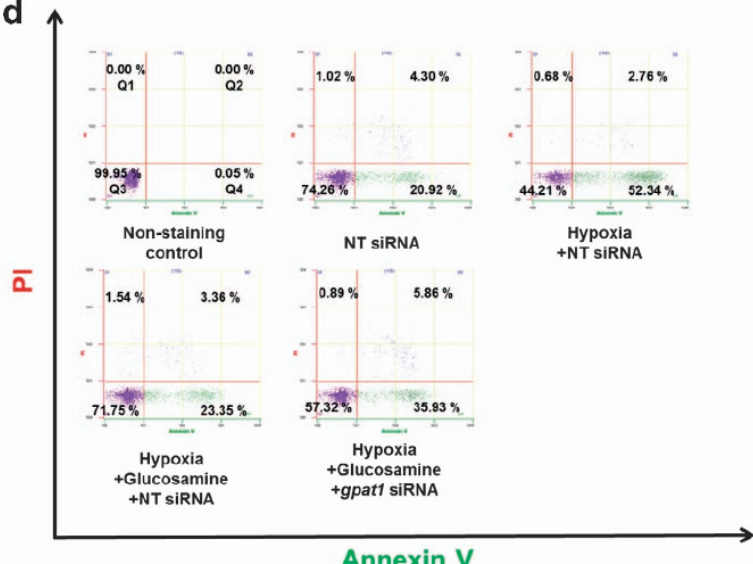

Annexin V

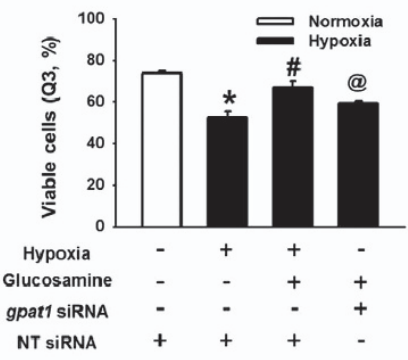

Figure 4 Role of GPAT1 in mESCs apoptosis under hypoxia. (a) Cells were pretreated with palmitic acid $(10 \mu \mathrm{M})$, oleic acid $(10 \mu \mathrm{M})$, and LPA (0.1 $\mu \mathrm{M})$ before hypoxia treatment for $24 \mathrm{~h}$. Cell viability was measured with trypan blue exclusion assay. Error bars are showed as a mean \pm S.E.M. of three independent experiments with duplex dishes. ${ }^{*} P<0.05$ versus control, ${ }^{\#} P<0.05$ versus hypoxia treatment alone. (b) Cells were transfected with gpat1 and non-targeting (NT) siRNA for $24 \mathrm{~h}$ before glucosamine (10 $\mu \mathrm{M}$ ) treatment for $30 \mathrm{~min}$, and then cells were exposed to hypoxia for $24 \mathrm{~h}$. Total lysates were blotted with GPAT1, Bcl-2, Bax, caspase-9, caspase-3, and $\beta$-actin. The NT siRNA was used as a negative control. Each blot was representative image of three independent experiments. ${ }^{*} P<0.05$ versus control, ${ }^{\#} P<0.05$ versus hypoxia treatment alone, and ${ }^{\circledR} P<0.05$ versus hypoxia with glucosamine. (c) Cell viability was measured directly by trypan blue exclusion assay using counting chamber. Data are presented as a mean \pm S.E.M. of three independent experiments with duplex dishes. ${ }^{*} P<0.05$ versus control, ${ }^{\#} P<0.05$ versus hypoxia treatment alone, and ${ }^{\circledR} P<0.05$ versus hypoxia with glucosamine. (d) Viable cells were measured by using annexin V/PI flow cytometry analysis. Annexin V-negative-PI-negative cells (Q3) were considered viable, annexin V-negative-PI-positive cells (Q1) were considered necrotic, annexin V-positive-PI-positive cells (Q2) were considered late apoptotic, and annexin V-positive-PI-negative cells (Q4) were considered early apoptotic. Data are presented as a mean \pm S.E.M. of two independent duplex dishes. ${ }^{*} P<0.05$ versus control, ${ }^{\#} P<0.05$ versus hypoxia treatment alone, and ${ }^{@} P<0.05$ versus hypoxia with glucosamine

Figure 3 Role of glucosamine-induced O-GIcNAcylation of SP1 in GPAT1 expression. Cells were pretreated with glucosamine $(10 \mu \mathrm{M})$ for 30 min before hypoxia treatment; and then, cells were exposed to hypoxia for $24 \mathrm{~h}$. (a) Total mRNA from mESCs was reverse-transcribed and fasn, acc1, cpt1a, cpt1b, magl, gpat1, gpat2, gpat3, gpat4, scd1, scd2, $s c d 3$, scd4, Ipaat $\alpha$, Ipaat $\beta$, Ipaat $\delta$, Ipaate, and $\beta$-actin mRNA amplified by PCR. The mRNA expression levels were measured by using real-time PCR. Each mRNA expression was normalized by $\beta$-actin mRNA expression level. Data are presented as a mean \pm S.E.M. of three independent duplex dishes. ${ }^{*} P<0.05$ versus control, ${ }^{\#} P<0.05$ versus hypoxia treatment alone, and ${ }^{\circledR} P<0.05$ versus hypoxia with glucosamine. (b) Cells were immune-stained with GPAT1 antibody and PI. Fluorescence intensity (ImageJ arbitrary units) of GPAT1 was analyzed by using ImageJ software (developed by Wayne Rasband, National Institutes of Health, Bethesda, MD, USA; http://rsb.info.nih.gov/ij/). The result images are representative of three independent experiments. Data are presented as a mean \pm S.E.M. of three independent experiments. ${ }^{*} P<0.05$ versus control, ${ }^{\#} P<0.05$ versus hypoxia treatment alone. Scale bars $=25 \mu \mathrm{m}$ (magnification $\times 800)$. (c) Cells were pretreated with ST045849 $(20 \mu \mathrm{M})$ for 30 min before glucosamine treatment $(10 \mu \mathrm{M})$ for $30 \mathrm{~min}$, and then cells were exposed to hypoxia for $24 \mathrm{~h}$. GPAT1 protein expression was measured by using western blotting. Each result shown is representative of three independent experiments. ${ }^{*} P<0.05$ versus control, ${ }^{\#} P<0.05$ versus hypoxia treatment alone, and ${ }^{\circledR} P<0.05$ versus hypoxia with glucosamine. (d) 0 -GlcNAcylation of Sp1 was measured with an immunoprecipitation assay as described in the Materials and methods section. RL-2, Sp1, and $\beta$-actin protein expressions were detected by western blotting. Each result shown is representative of three independent experiments. (e) Cells were pretreated with ST045849 $(20 \mu \mathrm{M})$ or PUGNAc (10 $\mu \mathrm{M})$ before glucosamine (10 $\mu \mathrm{M})$ treatment, and then cells were exposed to hypoxia for $24 \mathrm{~h}$. Collected cells were fractionized into non-nuclear and nuclear fractions. Sp1, $\beta$-actin, and lamin A/C were detected by western blotting. Each result shown is representative of three independent experiments. ${ }^{*} P<0.05$ versus control, ${ }^{\#} P<0.05$ versus hypoxia treatment alone, and ${ }^{\circledR} P<0.05$ versus hypoxia with glucosamine. (f) GPAT1 was detected by immune-staining with GPAT1 antibody. Fluorescence intensity of total GPAT1 and GPAT1 within nuclear region were analyzed by using ImageJ software. Error bars are presented as a mean \pm S.E.M. of three independent experiments. ${ }^{*} P<0.05$ versus control, ${ }^{\#} P<0.05$ versus hypoxia treatment alone. Scale bars $=25 \mu \mathrm{m}$ (magnification $\times 800$ ). (g) Cells were pretreated mithramycin $\mathrm{A}(1 \mu \mathrm{M})$ for 30 min before glucosamine $(10 \mu \mathrm{M})$ treatment for 30 min. Subsequently, cells were exposed to hypoxia for $24 \mathrm{~h}$. Total protein was extracted, and blotted with GPAT1. Each result shown is representative of three independent experiments 
may have clinical implications for stem cell-based treatments. To our knowledge, this is the first detailed identification of signaling pathways that allow glucosamine-induced O-GlcNAcylation to control lipid metabolic alteration and provide cytoprotection against hypoxia in stem cells (Figure 5j); thus, suggesting that lipid metabolic regulation via O-GIcNAcylation could be a novel strategy in stem cell therapy. Further investigation into the identification of key metabolic pathways that can regulate stem cell fate and function may hold additional promise for various stem cell applications. In conclusion, our results show that
O-GlcNAcylation of SP1-induced GPAT1 expression is critical for mESC survival via mTOR activation under hypoxia.

\section{Materials and Methods}

Materials. Cells from a mESC line (ES-E14TG2a) were provided by the American Type Culture Collection (Manassas, VA, USA). Fetal bovine serum was purchased from HyClone (Logan, UT, USA). The Bcl-2, Bax, caspase-3, caspase-9, Sp1, cytochrome C, COX IV, $\beta$-tubulin, Oct3/4, nanog, $\beta$-actin, and Lamin A/C antibodies were acquired from Santa Cruz Biotechnology (Dallas, TX, USA). The RL-2, Glycerol-3-phosphate acyltransferase-1 (GPAT1), and ALG10 antibodies were obtained from abcam (Cambridge, MA, USA). Mammalian target of rapamycin (mTOR), p-mTOR (Ser 2448), S6K1, p-S6K1 (Thr 389), 4EBP1, and p-4EBP1 a
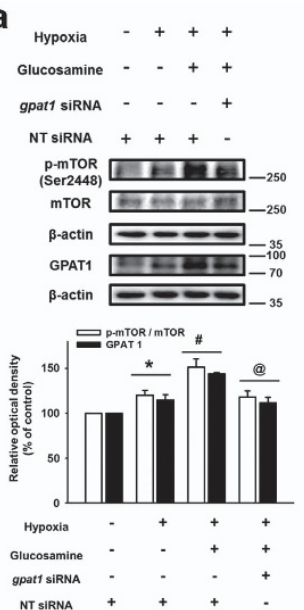

e

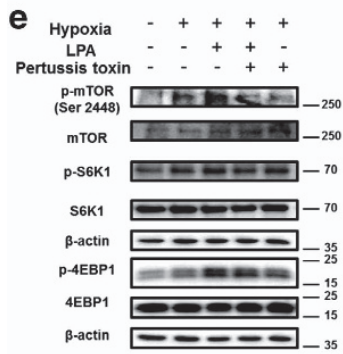

B-actin -15

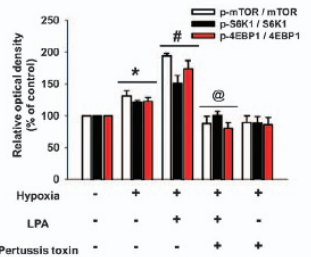

b

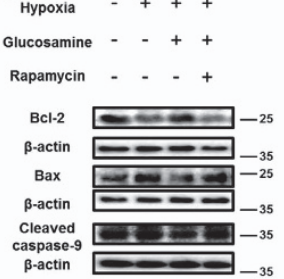

$\beta$-actin

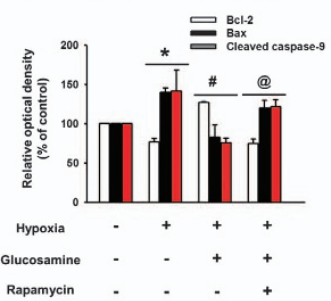

C

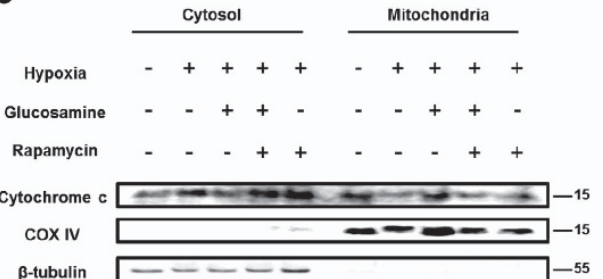

$\beta$-tubulin
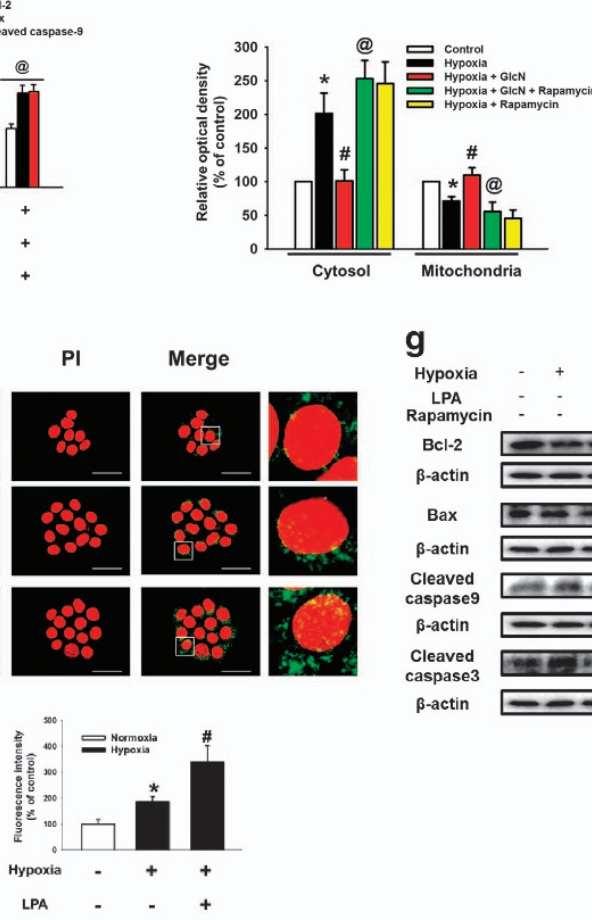

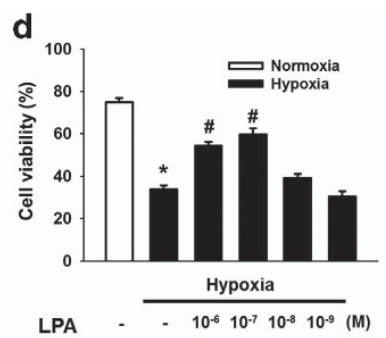

LPA

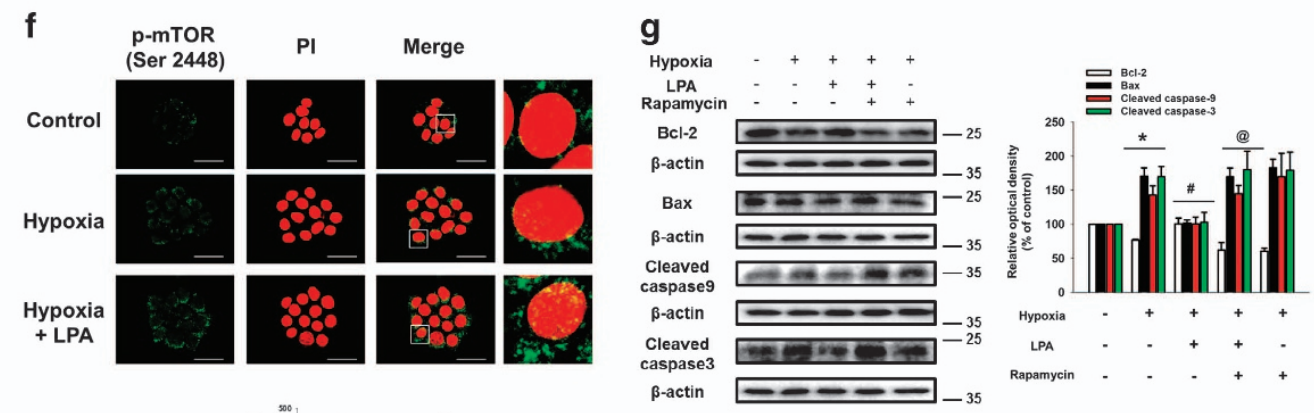

i
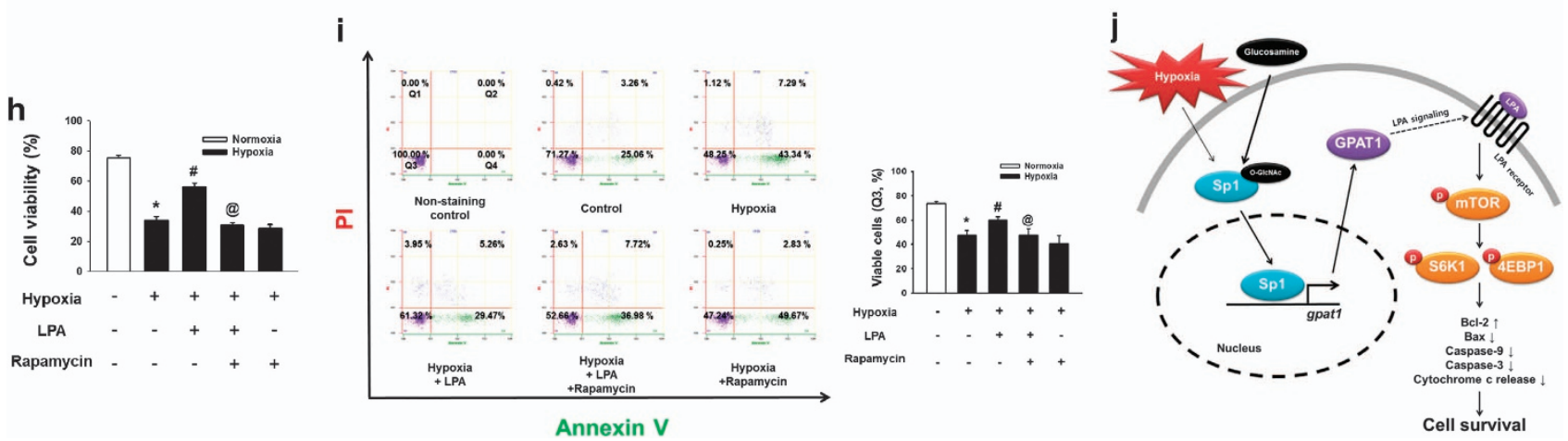
(Thr 37/46) antibodies were purchased from Cell Signaling Technology (Beverly, MA, USA). Horseradish peroxidase (HRP)-conjugated rabbit anti-mouse and goat anti-rabbit secondary antibodies were acquired from Thermo Fisher (Waltham, MA, USA), whereas HRP-conjugated rabbit anti-goat secondary antibody was obtained from Santa Cruz Biotechnology. Rapamycin, D-glucosamine, PUGNAc, N-acetyl D-glucosamine (GlcNAc), tunicamycin, lysophosphatidic acid (LPA), palmitic acid, oleic acid, mithramycin A, pertussis toxin (Ptx), SN-50, and bromodeoxyuridine (BrdU) were purchased from Sigma-Aldrich (St. Louis, MO, USA). The OGT inhibitor ST045849 was obtained from Timtec (Newark, DE, USA). Small interfering RNAs (siRNA) for gpat1 and non-targeting (NT) siRNA were acquired from Dharmacon (Lafayette, CO, USA). Propidium iodide (PI) and Alexa fluor 488conjugated secondary antibodies were purchased from Life technologies (Gaithersburg, MD, USA). All experiments were performed with 6-10 passages of the tested cells.

mESC culture. The mESCs were cultured with $15 \% \mathrm{FBS}, 1 \%$ antibiotic mixture, $5 \mathrm{ng} / \mathrm{ml}$ mouse leukemia inhibitory factor (LIF), and high glucose Dulbeco's essential medium (DMEM; Gibco, Grand Island, NY, USA). The cells were grown on six-well plates or in 35 or $60 \mathrm{~mm}$ culture dishes in an incubator maintained at $37^{\circ} \mathrm{C}$ with $5 \% \mathrm{CO}_{2}$. After $48 \mathrm{~h}$ of cell culture, cells were washed twice with phosphate buffered solution (PBS) and placed in DMEM-supplemented culture medium with $5 \%$ serum replacement, $1 \%$ antibiotics, and $5 \mathrm{ng} / \mathrm{ml}$ LIF (SR-medium). After cells were incubated $24 \mathrm{~h}$ for mESC synchronization, cells were washed twice with PBS and placed in SR-medium with agents.

Hypoxia treatment. For hypoxia treatment, a modular incubation chamber (Billups-Rothenberg, Del Mar, CA, USA) was used. The hypoxic gas included 2.2\% $\mathrm{O}_{2}, 5.5 \% \mathrm{CO}_{2}$, and $92.3 \% \mathrm{~N}_{2}$. Synchronized mESCs were placed in the incubation chamber, and the chamber was purged with the hypoxic gas at a rate of $5 \mathrm{l} / \mathrm{min}$ for $30 \mathrm{~min}$. The chamber was then sealed and placed in a conventional incubator kept at $37^{\circ} \mathrm{C}$.

Mouse skin flap model. All procedures using animals followed the National Institutes of Health Guidelines for the Humane Treatment of Animals and were performed under Institutional Animal Care and Use Committee-approved protocols at Seoul National University (SNU-150508-4). Mice were housed in a standard animal facility maintained on a $12 \mathrm{~h}$ light/dark cycle and within a room temperature range of $20-25^{\circ} \mathrm{C}$. Eight-week-old male Institute for Cancer Research mice were anesthetized with $2 \%$ isoflurane in oxygen/nitrous oxide mixtures. A previously described skin flap model procedure was performed. ${ }^{76-78}$ Experimental animals were divided into seven groups: vehicle-injected wild-type mice (group 1, $n=6$ ); $\mathrm{mESC}$ transplantation mice that received mESC pretreated with either NT siRNA alone (group 2, $n=6$ ) or NT siRNA and $10 \mu \mathrm{M}$ glucosamine (group 3, $n=6$ ); mice that received mESC pretreated with gpat1 siRNA and $10 \mu \mathrm{M}$ glucosamine (group 4, $n=6$ ); mice that received $10 \mu \mathrm{M}$ glucosamine with vehicle (group $5, n=6$ ); mice that received mESC pretreated with $0.1 \mu \mathrm{M} \mathrm{LPA}$ (group 6, $n=6$ ); and mice that received $0.1 \mu \mathrm{M}$ LPA with vehicle (group $7, n=6$ ). After shaving off the hair, a $4 \mathrm{~cm} \times 1 \mathrm{~cm}$ skin flap template on the dorsal surface of the mouse was traced by using a surgical marker. The surgical procedure for flap creation was performed under aseptic conditions. A full-thickness skin flap was elevated for $30 \mathrm{~min}$. For treatment, $100 \mu \mathrm{l}$ of a PBS and matrigel (BD Biosciences, Franklin Lakes, NJ, USA) mixture containing vehicle or mESCs $\left(n=1 \times 10^{6}\right)$ with either glucosamine or LPA was injected into the dermis at the center of the skin flap. The flap was then sutured back to its original position by a simple interrupted suturing technique using 3-0 silk non-absorbable sutures (Figure 6a). Transplanted mESCs were pretreated with $\operatorname{BrdU}(2 \mu \mathrm{M})$. All flap images were acquired at the same distance from the subject $(30 \mathrm{~cm})$ with a digital camera system (D50; Nikon, Tokyo, Japan). At post-injection day 12, all mice were killed and $1.5 \mathrm{~cm} \times 0.5 \mathrm{~cm}$ tissue samples in the central part of the skin flap were excised and collected (Figure 6a). Collected tissues were embedded in O.C.T compound (Sakura Finetek, Torrance, CA, USA) and frozen. Embedded samples were sliced (10- $\mu \mathrm{m}$ thick), and underwent hematoxylin and eosin (H\&E) and immunohistochemical $(\mathrm{IHC})$ staining. Sliced samples for $\mathrm{IHC}$ analysis were immunostained with BrdU and PI. Immunostained cells were visualized by using fluorescence microscopy (Olympus, Tokyo, Japan), and the images were analyzed by using MetaMorph software (Universal Imaging, West Chester, PA, USA). Visual assessment of skin flap necrotic areas was performed by using ImageJ software (developed by Wayne Rasband, National Institutes of Health, Bethesda, MD, USA; http://rsb.info.nih.gov/ij/). Dark areas with scabs in a skin flap were considered necrotic. To determine the portion of the skin flap that was necrotic, we used the formula: Necrotic area in skin flap = necrotic area of flap area/area of total flap $\times 100$.

Western blot analysis. After normoxic or hypoxic incubation, cells were collected by using a cell-collecting scraper. Collected samples were washed twice with ice-cold PBS prior to incubation in RIPA lysis buffer (Thermo Fisher) containing proteinase and phosphatase inhibitor (Thermo Fisher) for 30 min on ice. Next, the lysates were centrifugated for clearance (15000 r.p.m. at $4{ }^{\circ} \mathrm{C}$ for $30 \mathrm{~min}$ ). The protein concentration in the lysate was determined by using a bicinchoninic acid assay kit (Bio-Rad, Hercules, CA, USA). Obtained protein $(10 \mu \mathrm{g})$ was then loaded in 10\% SDS-polyacryl-amide gel for electrophoresis and transferred to a polyvinylidene fluoride (PVDF) membrane. The protein-transferred membrane was washed with tris-buffered saline containing a $0.1 \%$ Tween-20 (TBST) solution (10 mM Tris- $\mathrm{HCl}(\mathrm{pH} 7.6), 150 \mathrm{mM} \mathrm{NaCl}$, and 0.1\% Tween-20) and blocked with 5\% skim milk or $5 \%$ bovine serum albumin for $15 \mathrm{~min}$. The membranes were then washed with TBST solution for $30 \mathrm{~min}$ and incubated with primary antibody (1:1000 dilution) overnight at $4{ }^{\circ} \mathrm{C}$. The membranes were washed again and then incubated with HRP-conjugated secondary antibody $\left(1: 10000\right.$ dilution) for $6 \mathrm{~h}$ at $4{ }^{\circ} \mathrm{C}$. The western blotting bands were detected by using enhanced chemiluminescence (Bio-Rad). Densitometric analysis of western blotting bands was quantified by using ImageJ software.

Figure 5 Involvement of mTOR in GPAT1-induced mESCs anti-apoptosis under hypoxia. (a) Cells were transfected with gpat1 and NT siRNA for $24 \mathrm{~h}$ before glucosamine $(10 \mu \mathrm{M})$ for $30 \mathrm{~min}$. Subsequently, cells were exposed to hypoxia treatment for $24 \mathrm{~h}$. Collected samples are lysed, and p-mTOR, GPAT1, and $\beta$-actin protein expressions were measured by using western blotting. Each result shown is representative of three independent experiments. ${ }^{*} P<0.05$ versus control, ${ }^{\#} P<0.05$ versus hypoxia treatment alone, and ${ }^{\circledR} P<0.05$ versus hypoxia with glucosamine. (b) Cells were pretreated with rapamycin $(10 \mathrm{nM})$ before glucosamine $(10 \mu \mathrm{M})$ treatment; and then, cells were exposed to hypoxia for $24 \mathrm{~h}$. Total proteins were extracted, and blotted with Bcl-2, Bax, cleaved caspase-9, and $\beta$-actin. Each result shown is representative of three independent experiments. (c) Cells were pretreated with glucosamine and/or rapamycin $(10 \mathrm{nM})$ for 30 min before hypoxia treatment, and cytochrome c, COX IV, and $\beta$-tubulin in the cytosolic and mitochondrial fraction were detected by western blot. (d) Cells were pretreated with various concentrations of LPA $\left(10^{-6} \mathrm{M}-10^{-9} \mathrm{M}\right)$ before hypoxia treatment for $24 \mathrm{~h}$. Cell viability was measured by trypan blue exclusion assay. Error bars are presented as a mean \pm S.E.M. of three independent duplex dishes. ${ }^{*} P<0.05$ versus control, ${ }^{\#} P<0.05$ versus hypoxia treatment alone. (e) Cells were pretreated with pertussis toxin (100 ng/ml) for $30 \mathrm{~min}$ before LPA treatment $(0.1 \mu \mathrm{M})$ for 30 min. Subsequently, cells were exposed to hypoxia treatment for $24 \mathrm{~h}$. Total proteins were extracted and blotted with $\mathrm{p}$-mTOR, mTOR, $\mathrm{p}$-S6K1, S6K1, p-4EBP1, 4EBP1, and $\beta$-actin. Each result shown is representative of three independent experiments. ${ }^{*} P<0.05$ versus control, ${ }^{\#} P<0.05$ versus hypoxia treatment alone, and ${ }^{\circledR} P<0.05$ versus hypoxia with LPA. (f) $p$-mTOR was immunostained with $p$-mTOR antibody, and counter-stained with PI. Fluorescence images were acquired by using confocal microscopy. Fluorescence intensity of $p$-mTOR was quantified by using ImageJ software. Data are presented as a mean \pm S.E.M. of three independent experiments. ${ }^{*} P<0.05$ versus control, ${ }^{\#} P<0.05$ versus hypoxia treatment alone. (g) Cells were pretreated with rapamycin $(10 \mathrm{nM})$ before LPA $(0.1 \mu \mathrm{M})$ treatment; and then, cells were exposed to hypoxia for $24 \mathrm{~h}$. Total proteins were extracted, and blotted with Bcl-2, Bax, cleaved caspase-9, cleaved caspase-3, and $\beta$-actin. Each result shown is representative of three independent experiments. (h) Cell viability was measured by using cell counter. Data are presented as a mean \pm S.E.M. of three independent duplex dishes. ${ }^{\star} P<0.05$ versus control, ${ }^{\sharp} P<0.05$ versus hypoxia treatment alone, and ${ }^{\circledR} P<0.05$ versus hypoxia with LPA. (i) Viable cells were measured by using annexin V/PI flow cytometry analysis. Annexin V-negative-PI-negative cells (Q3) were considered viable, annexin V-negative-PIpositive cells (Q1) were considered necrotic, annexin V-positive-PI-positive cells (Q2) were considered late apoptotic, and annexin V-positive-PI-negative cells (Q4) were considered early apoptotic. Data are presented as a mean \pm S.E.M. of two independent duplex dishes. ${ }^{*} P<0.05$ versus control, ${ }^{\#} P<0.05$ versus hypoxia treatment alone, and ${ }^{\circledR} P<0.05$ versus hypoxia with LPA. ${ }^{\star} P<0.05$ versus control, ${ }^{\#}$ indicates $P<0.05$ versus hypoxia treatment alone, and ${ }^{\circledR} P<0.05$ versus hypoxia with LPA. The proposed model for signaling pathways involved in glucosamine-induced mESCs survival under hypoxia (j) 
a

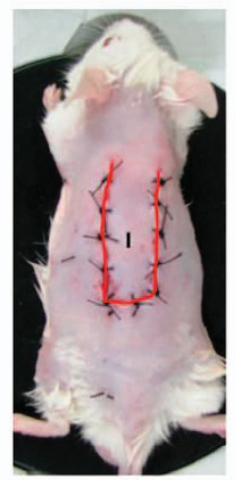

Day 0

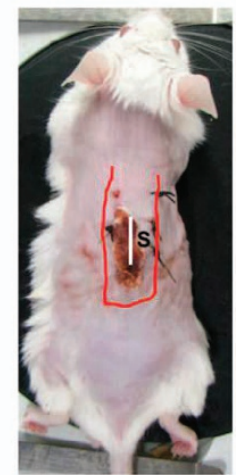

Day 12

b
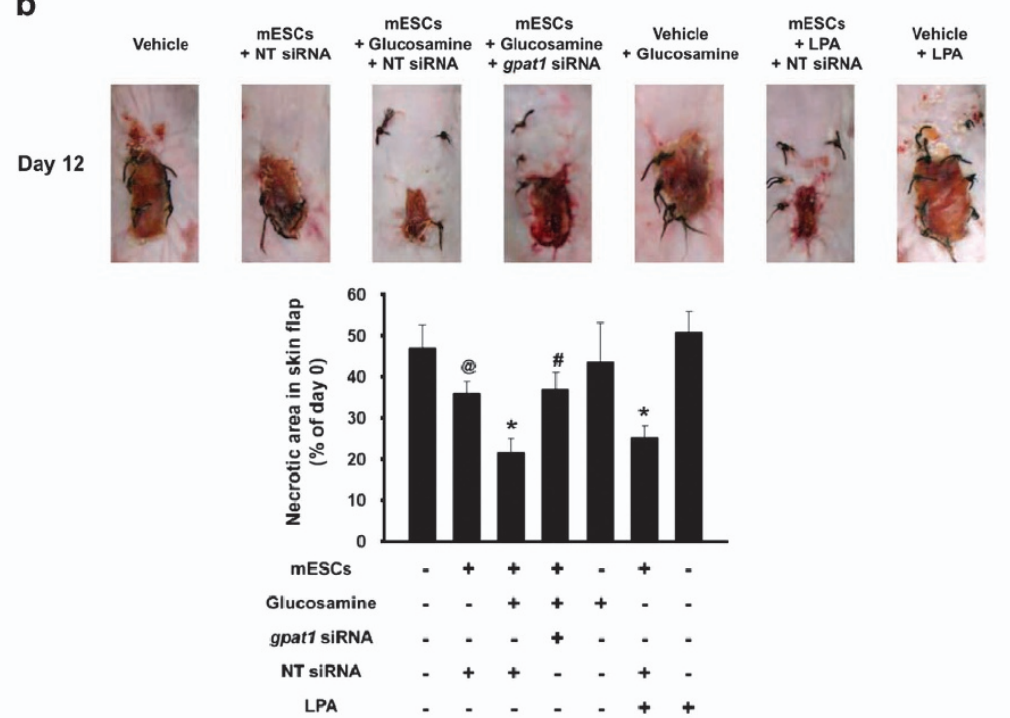

C

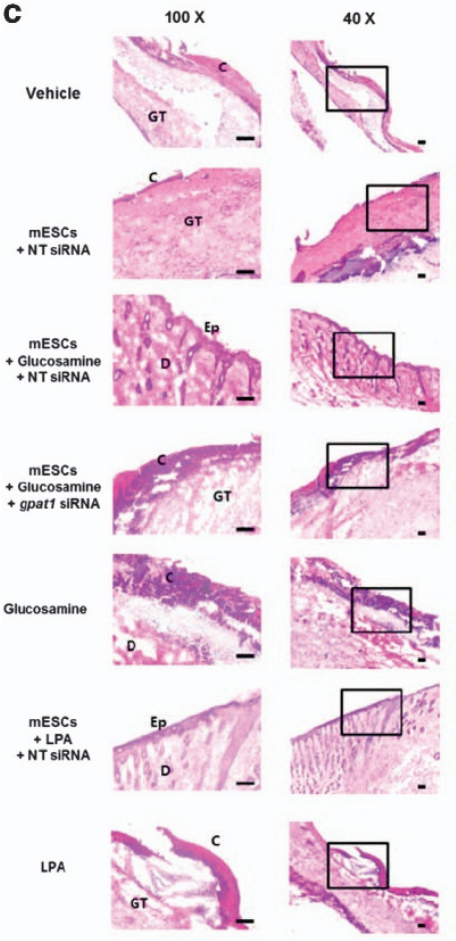

d
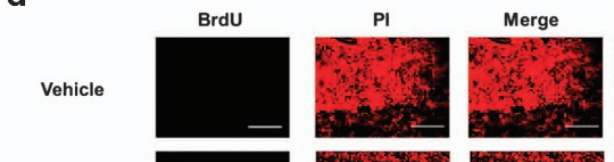

Low magnification

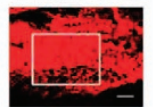

mESCs
+ NT siRNA

mESCs
+ Glucosami
+

Glucosamine
+ NT siRNA

+ NT SiRNA

mESCs

+ Glucosamine
+ gpat1 siRNA

Vehicle
+ Glucosami

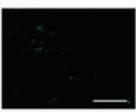

5

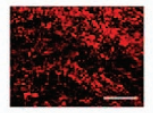

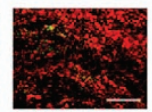
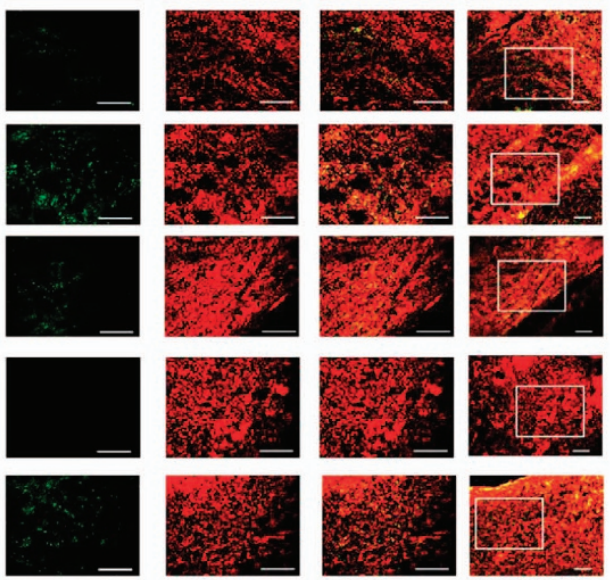

mESCs

+ LPA

+ NT SiRNA

Vehicle
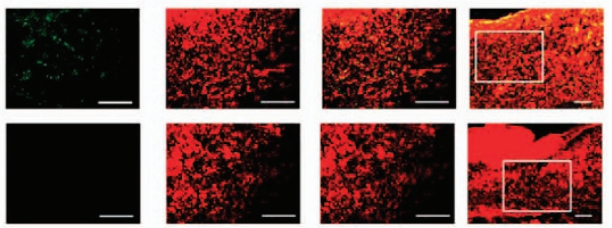

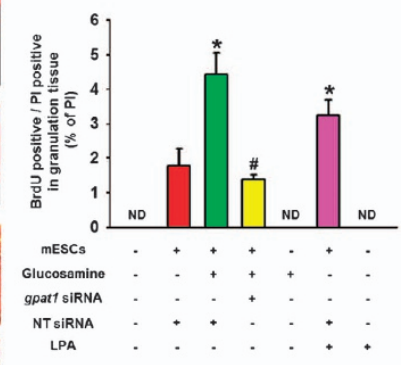

Figure 6 Role of GPAT1 in mESCs survival in the mouse skin flap model. Mouse skin flap surgery with BrdU-harbored mESCs transplantation was performed as described in Materials and methods section. (a) NT siRNA-transfected cells are injected in the center region (I) of the flap. At post-injection day 12, all tissue samples (S) including injection site in are excised and collected. (b) Representative gross images of skin flap were obtained at day 12 after flap surgery. Necrotic area in skin flap was analyzed by using Image software. Error bars indicate a mean \pm S.E.M. $n=5$. ${ }^{\circledR} P<0.05$ versus vehicle group, ${ }^{*} P<0.05$ versus mESCs group, and ${ }^{\sharp} P<0.05$ versus mESCs with glucosamine group. (c) Tissue samples were stained with hematoxylin and eosin. Histological images shown in result are representative. Scale bars, $100 \mu \mathrm{m}$ (magnification, $\times 40$ and $\times 100)$. (d) BrdU was immunostained with BrdU specific antibody and PI for nuclear counting, and samples were visualized by using confocal microscopy. BrdU and Pl-stained cells were analyzed by using MetaMorph software. Scale bars, $200 \mu \mathrm{m}$ (magnification, $\times 100$ and $\times 200$ ). ${ }^{*} P<0.05$ versus mESCs group, and ${ }^{\#} P<0.05$ versus mESCs with glucosamine group. C, crust; Ep, epidermis; D, dermis; GT, granulated tissue; ND, not detected

Nuclear and Non-nuclear fraction preparation. Harvested samples were suspended in buffer A solution ( $137 \mathrm{mM} \mathrm{NaCl}, 8.1 \mathrm{mM} \mathrm{Na}_{2} \mathrm{HPO}_{4}, 2.7 \mathrm{mM} \mathrm{KCl}$, $1.5 \mathrm{mM} \mathrm{KH}_{2} \mathrm{PO}_{4}, 2.5 \mathrm{mM}$ EDTA, $1 \mathrm{mM}$ dithiothreitol, $0.1 \mathrm{mM} \mathrm{PMSF}$, and $10 \mathrm{mg} / \mathrm{ml}$ leupeptin ( $\mathrm{pH} 7.5)$ ). Suspended cells were homogenized mechanically by using a 23-gauge needle and then incubated for $10 \mathrm{~min}$. Cell lysates were centrifugated at 8000 r.p.m. for $5 \mathrm{~min}$ at $4^{\circ} \mathrm{C}$. Supernatant, as the non-nuclear fraction, was collected. The obtained pellet, as the nuclear fraction, was then lysed with RIPA lysis buffer containing proteinase and phosphatase inhibitor.

Isolation of mitochondria. Samples were extracted using the commercial mitochondria isolation kit for cultured cells (Thermo Fisher) according to the manufacturer's manual. Collected cells were suspended in Reagent $A$, and then 
incubated for 2 min on ice. Reagent B was added to samples, and then incubated for $5 \mathrm{~min}$. Subsequently, Reagent $\mathrm{C}$ was added to samples. Cell lysates were centrifugated at $3000 \mathrm{~g}$ for $15 \mathrm{~min}$. Supernatant, as cytosol fraction, was collected. The obtained pellet, as mitochondrial fraction, was then lysed with $2 \%$ CHAPS in Tris-buffered saline (25 mM Tris, $0.15 \mathrm{M} \mathrm{NaCl}$; pH 7.2).

Immunoprecipitation. Collected cells were lysed with non-denaturing lysis buffer (20 mM Tris- $\mathrm{HCl} \mathrm{pH8,} 136 \mathrm{mM} \mathrm{NaCl}, 1 \% \mathrm{NP} 40$, and $2 \mathrm{mM} \mathrm{EDTA}$ ) including proteinase and phosphatase inhibitor. Immunoprecipitation lysates were incubated with an appropriate primary antibody overnight. Subsequently, Protein A/G PLUSAgarose immunoprecipitation reagents (Santa Cruz Biotechnology) were added to lysates for $4 \mathrm{~h}$. Samples were washed twice with non-denaturing lysis buffer. Similar amounts of samples were loaded in 10\% SDS-polyacryl-amide gel for electrophoresis and then transferred to a PVDF membrane. Blotting bands were visualized with an enhanced chemiluminescence solution (Bio-Rad).

mRNA isolation and reverse transcription polymerase chain reaction. The mESC RNA was extracted by using the RNeasy Plus Mini Kit (QIAGEN, Valencia, CA, USA). Extracted RNA $(1 \mu \mathrm{g})$ was reverse-transcripted with a Maxime RT premix kit (iNtRON Biotechnology, Sungnam, Korea). The cDNA was amplified with the sense and antisense primers of gpat1 and $\beta$-actin.

Real-Time PCR. Expressions of the fasn, acc1, cpt1a, cpt1b, magl, gpat1, gpat2, gpat3, gpat4, scd1, scd2, scd3, scd4, Ipaat $\alpha$, Ipaat $\beta$, Ipaat $\delta$, Ipaate, and $\beta$-actin genes were detected by using a Rotor-Gene 6000 real-time thermal cycling system (Corbett Research, Mortlake, NSW, Australia) with a QuantiMix SYBR kit (Phile Korea Technology, Daejeon, Korea), mRNA primers, and $1 \mu \mathrm{g}$ of the cDNA sample. Data were analyzed by using the manufacture's software (Corbett Research). Melting curve analysis was used to confirm the identity and specificity of the PCR products. Normalization was performed by using $\beta$-actin as the endogenous control. Primer sequences used in experiments are described in Supplementary Table S1.

Small interfering RNA transfection. Prior to transplantation or hypoxia treatment, siRNAs specific for gpat1 or NT siRNA as a negative control were transfected to $\mathrm{mESCs}$ for $24 \mathrm{~h}$ with HiPerfect transfection reagent (QIAGEN) according to the manufacturer's description. Each transfected siRNA's concentration was $25 \mathrm{nM}$. The siRNA sequences are described in Supplementary Table S2.

Trypan blue exclusion cell viability assay. Cell-cultured medium was collected and the cells were washed twice with ice-cold PBS. Washed cells were suspended with a $0.05 \%$ Trypsin and $0.5 \mathrm{mM}$ EDTA solution. The collected medium was added to the cell suspension solution, including detached cells, and the mixture was treated with soybean trypsin inhibitor $(0.05 \mathrm{mg} / \mathrm{ml})$ to quench trypsin activity. Trypan blue (0.4\%; Sigma-Aldrich) was added to the cell suspension to stain the dead cells. Stained cells and all cells were counted by using a Petroff-Hausser counting chamber (Hausser Scientific, Horsahm, PA, USA). Cell viability was determined by using the following formula. Cell viability $=[1-$ (number of trypan blue-stained cells/number of total cells) $\times 100]$.

Annexin V/PI Fluorescence-activated cell sorter analysis. Annexin and $\mathrm{PI}$ staining was performed by using Annexin $\mathrm{V}$ and $\mathrm{PI}$ staining kit (BD Bioscience) according to the manufacturer's instruction. Briefly, cell-cultured medium was collected. The mESCs were detached with a $0.05 \%$ Trypsin and $0.5 \mathrm{mM}$ EDTA solution and the collected medium was added to the cell suspension, followed by the addition of soybean trypsin inhibitor $(0.05 \mathrm{mg} / \mathrm{ml})$. Next, $1 \times 10^{5}$ cells were resuspended in $1 \times$ binding buffer, immunostained with $5 \mu$ l of FITC Annexin V and $5 \mu \mathrm{l}$ of $\mathrm{Pl}$, and incubated at $25^{\circ} \mathrm{C}$ for $15 \mathrm{~min}$ in the dark. Analysis was performed by using flow cytometry (Beckman Coulter, Fullerton, CA, USA). From each sample, $5 \times 10^{3}$ cells were obtained and analyzed by using CXP software (Beckman Coulter).

Intracellular reactive oxygen species (ROS) detection. Intracellular ROS was detected by using CM- H$_{2}$ DCF-DA (DCF-DA, Life Technologies, Gaithersburg, MD, USA), a $\mathrm{H}_{2} \mathrm{O}_{2}$-sensitive fluorophore. Cells were detached with a $0.05 \%$ Trypsin and $0.5 \mathrm{mM}$ EDTA solution, and $5 \times 10^{5}$ cells were resuspended in $10 \mu \mathrm{M}$ DCF-DA in PBS and incubated at $25^{\circ} \mathrm{C}$ for $30 \mathrm{~min}$ in the dark. In order to quantify the intracellular ROS levels, the cells were rinsed twice with ice-cold PBS followed by resuspension in ice-cold PBS. A $150 \mu$ laliquot of cell suspension was loaded into a 96-well plate and fluorescence was detected by using a luminometer
(Victor3, Perkin-Elmer, Waltham, MA, USA) with excitation and emission wavelengths of 485 and $535 \mathrm{~nm}$, respectively.

Immunofluorescence staining. Cells were fixed with $80 \%$ acetone in PBS for $10 \mathrm{~min}$, followed by washing with PBS. Sequentially, cells were incubated with $5 \%$ normal goat serum to inhibit non-specific binding of antibody, and then incubated with primary antibody (1:100 dilution) overnight at $4{ }^{\circ} \mathrm{C}$. Next, the cells were incubated for $1 \mathrm{~h}$ with Alexa flour 488-conjugated anti-rabbit and anti-mouse IgG secondary antibody (1:100 dilution, Life Technologies) and PI in PBS. Images were acquired via a FluoView 300 fluorescence microscope (Olympus). For quantification of protein expression, we calculated the corrected total cell fluorescence (CTCF, ImageJ arbitrary unit) by using ImageJ software. The equation used to determine CTCF was CTCF $=$ Integrated density - (Area of selected cell $\times$ Mean fluorescence of background readings). Three independent experiments were performed, and the CTCF of 15 colonies ( 5 colonies per experiment) were obtained.

Live-cell imaging. After glucosamine or LPA treatment, the culture dish was placed in a temperature and $\mathrm{CO}_{2}$ control chamber (Tokai, Tokyo, Japan). Normoxic or hypoxic gas was supplied for $48 \mathrm{~h}$. Differential interference contrast images were acquired over those $48 \mathrm{~h}$ at $10 \mathrm{~min}$ intervals by using an Olympus IX81-ZDC zerodrift microscope and a Cascade 512B camera (Roper Scientific, Tucson, AZ, USA). A constant threshold of each image was maintained. Determination of the mESC colony area was performed by using ImageJ software.

$\left[{ }^{3} \mathrm{H}\right]$-Thymidine incorporation. After treatment, the mESCs were treated with $1 \mu \mathrm{Ci}$ of [methyl- ${ }^{3} \mathrm{H}$ ]-thymidine (Amersham Biosciences, Piscataway, $\mathrm{NJ}$, USA), and incubated for $1 \mathrm{~h}$ at $37^{\circ} \mathrm{C}$. The mESCs were washed with cold PBS, fixed in $10 \%$ trichloroacetic acid for $1 \mathrm{~h}$, and then washed with cold PBS. The acid-insoluble substance was lysed with $2 \mathrm{~N} \mathrm{NaOH}$ for $4 \mathrm{~h}$. The level of $\left[{ }^{3} \mathrm{H}\right]$-thymidine incorporation with DNA was detected using a liquid scintillation counter. Data were normalized from absolute counts to controls.

Statistical analysis. All experimental data are summarized as a mean \pm standard error. Differences among experimental groups were tested by using ANOVA. To compare some treatment group means with either control or hypoxia treatment means, the Bonferroni-Dunn test was performed. A test result with a $P$-value $<0.05$ was considered significant.

\section{Conflict of Interest}

The authors declare no conflict of interest.

Acknowledgements. This research was supported by National R\&D Program through the National Research Foundation of Korea (NRF) funded by the Ministry of Science, ICT \& Future Planning (NRF-2013M3A9B4076520), and BK21 PLUS Program for Creative Veterinary Science Research.

\section{Author contributions}

LHJ: conception and design, collection and/or assembly, analysis and interpretation of data, manuscript writing; RJM: conception and design, data analysis and interpretation, manuscript writing; JYH: data analysis and interpretation; LKH and $\mathrm{KDI}$ : collection and/or assembly of data; HHJ: conception and design, manuscript writing.

\section{Disclaimer}

The funders had no role in study design, data collection or analysis, the decision to publish, or manuscript preparation.

1. Simon MC, Keith $B$. The role of oxygen availability in embryonic development and stem cell function. Nat Rev Mol Cell Biol 2008; 9: 285-296.

2. Ito K, Suda T. Metabolic requirements for the maintenance of self-renewing stem cells. Nat Rev Mol Cell Biol 2014; 15: 243-256.

3. Forsyth NR, Musio A, Vezzoni P, Simpson AH, Noble BS, McWhir J. Physiologic oxygen enhances human embryonic stem cell clonal recovery and reduces chromosomal abnormalities. Cloning Stem Cells 2006; 8: 16-23.

4. Theus MH, Wei L, Cui L, Francis K, Hu X, Keogh C et al. In vitro hypoxic preconditioning of embryonic stem cells as a strategy of promoting cell survival and functional benefits after transplantation into the ischemic rat brain. Exp Neurol 2008; 210: 656-670.

5. Yoshida Y, Takahashi K, Okita K, Ichisaka T, Yamanaka S. Hypoxia enhances the generation of induced pluripotent stem cells. Cell Stem Cell 2009; 5: 237-241. 
6. Song H, Cha MJ, Song BW, Kim IK, Chang W, Lim S et al. Reactive oxygen species inhibit adhesion of mesenchymal stem cells implanted into ischemic myocardium via interference of focal adhesion complex. Stem Cells 2010; 28: 555-563.

7. Csete M. Oxygen in the cultivation of stem cells. Ann N Y Acad Sci 2005; 1049: 1-8.

8. Holbrook NJ, Ikeyama S. Age-related decline in cellular response to oxidative stress: links to growth factor signaling pathways with common defects. Biochem Pharmacol 2002; 64 999-1005.

9. Kumar S, Ashraf M. Tadalafil, a phosphodiesterase inhibitor protects stem cells over longer period against hypoxia/reoxygenation injury through STAT3/PKG-I signaling. Stem Cells Dev 2015; 24: 1332-1341.

10. Teslaa T, Teitell MA. Pluripotent stem cell energy metabolism: an update. EMBO J 2015; 34 138-153.

11. Lee HJ, Ryu JM, Jung YH, Oh SY, Lee SJ, Han HJ. Novel pathway for hypoxia-induced proliferation and migration in human mesenchymal stem cells: involvement of HIF-1 $\alpha, \mathrm{FASN}$, and mTORC1. Stem Cells 2015; 33: 2182-2195.

12. Wells L, Vosseller K, Hart GW. Glycosylation of nucleocytoplasmic proteins: signal transduction and O-GlcNAc. Science 2001; 291: 2376-2378.

13. Hart GW, Housley MP, Slawson C. Cycling of O-linked $\beta$-N-acetylglucosamine on nucleocytoplasmic proteins. Nature 2007; 446: 1017-1022.

14. Love DC, Hanover JA. The hexosamine signaling pathway: deciphering the "OGICNAc code". Sci STKE 2005; 2005: re13.

15. Guillaumond F, Leca J, Olivares O, Lavaut MN, Vidal N, Berthezene P et al. Strengthened glycolysis under hypoxia supports tumor symbiosis and hexosamine biosynthesis in pancreatic adenocarcinoma. Proc Natl Acad Sci USA 2013; 110: 3919-3924.

16. Dorfman A, Roseman S, Moses FE, Ludowieg J, Mayeda M. The biosynthesis of hyaluronic acid by group A Streptococcus. II. Origin of the $\mathrm{N}$-acetylglucosamine moiety. J Biol Chem 1955; 212: 583-591.

17. Marshall S, Bacote V, Traxinger RR. Discovery of a metabolic pathway mediating glucoseinduced desensitization of the glucose transport system. Role of hexosamine biosynthesis in the induction of insulin resistance. J Biol Chem 1991; 266: 4706-4712.

18. Ghosh S, Blumenthal HJ, Davidson E, Roseman S. Glucosamine metabolism. V Enzymatic synthesis of glucosamine 6-phosphate. J Biol Chem 1960; 235: 1265-1273.

19. Shafi R, lyer SP, Ellies LG, O'Donnell N, Marek KW, Chui D et al. The O-GlcNAc transferase gene resides on the $\mathrm{X}$ chromosome and is essential for embryonic stem cell viability and mouse ontogeny. Proc Natl Acad Sci USA 2000; 97: 5735-5739.

20. Jeon JH, Suh HN, Kim MO, Han HJ. Glucosamine-induced reduction of integrin $\beta 4$ and plectin complex stimulates migration and proliferation in mouse embryonic stem cells. Stem Cells Dev 2013; 22: 2975-2989.

21. Zafir A, Readnower R, Long BW, McCracken J, Aird A, Alvarez A et al. Protein O-GlcNAcylation is a novel cytoprotective signal in cardiac stem cells. Stem Cells 2013; 31: 765-775.

22. Liu J, Pang Y, Chang T, Bounelis P, Chatham JC, Marchase RB. Increased hexosamine biosynthesis and protein O-GIcNAc levels associated with myocardial protection against calcium paradox and ischemia. J Mol Cell Cardiol 2006; 40: 303-312.

23. Hardiville $S$, Hart GW. Nutrient regulation of signaling, transcription, and cell physiology by O-GIcNAcylation. Cell Metab 2014; 20: 208-213.

24. Ruan HB, Singh JP, Li MD, Wu J, Yang X. Cracking the O-GlcNAc code in metabolism Trends Endocrinol Metab 2013; 24: 301-309.

25. Ito K, Carracedo A, Weiss D, Arai F, Ala U, Avigan DE et al. A PML-PPAR- $\delta$ pathway for fatty acid oxidation regulates hematopoietic stem cell maintenance. Nat Med 2012; 18: 1350-1358.

26. Folmes CD, Park S, Terzic A. Lipid metabolism greases the stem cell engine. Cell Metab 2013; 17: 153-155

27. O'Shea KS. Self-renewal vs. differentiation of mouse embryonic stem cells. Biol Reprod 2004; 71: 1755-1765.

28. Chambers I. The molecular basis of pluripotency in mouse embryonic stem cells. Cloning Stem Cells 2004; 6: 386-391.

29. Murry CE, Keller G. Differentiation of embryonic stem cells to clinically relevant populations: lessons from embryonic development. Cell 2008; 132: 661-680.

30. Lee KB, Choi J, Cho SB, Chung JY, Moon ES, Kim NS et al. Topical embryonic stem cells enhance wound healing in diabetic rats. J Orthop Res 2011; 29: 1554-1562.

31. Hodgson DM, Behfar A, Zingman LV, Kane GC, Perez-Terzic C, Alekseev AE et al. Stable benefit of embryonic stem cell therapy in myocardial infarction. Am J Physiol Heart Circ Physiol 2004; 287: H471-H479.

32. Laflamme MA, Chen KY, Naumova AV, Muskheli V, Fugate JA, Dupras SK et al. Cardiomyocytes derived from human embryonic stem cells in pro-survival factors enhance function of infarcted rat hearts. Nat Biotechnol 2007; 25: 1015-1024.

33. Koay EJ, Athanasiou KA. Hypoxic chondrogenic differentiation of human embryonic stem cells enhances cartilage protein synthesis and biomechanical functionality. Osteoarthritis Cartilage 2008; 16: 1450-1456

34. Khan WS, Adesida AB, Hardingham TE. Hypoxic conditions increase hypoxia-inducible transcription factor $2 \alpha$ and enhance chondrogenesis in stem cells from the infrapatellar fat pad of osteoarthritis patients. Arthritis Res Ther 2007; 9: R55.

35. Arnaboldi PM, Behr MJ, Metzger DW. Mucosal B cell deficiency in IgA-/- mice abrogates the development of allergic lung inflammation. J Immunol 2005; 175: 1276-1285.

36. Pouwels MJ, Jacobs JR, Span PN, Lutterman JA, Smits P, Tack CJ. Short-term glucosamine infusion does not affect insulin sensitivity in humans. J Clin Endocrinol Metab 2001; 86: 2099-2103.
37. Mishra OP, Randis T, Ashraf QM, Delivoria-Papadopoulos M. Hypoxia-induced Bax and Bcl2 protein expression, caspase- 9 activation, DNA fragmentation, and lipid peroxidation in mitochondria of the cerebral cortex of newborn piglets: the role of nitric oxide. Neuroscience 2006; 141: 1339-1349.

38. Chen YJ, Huang YS, Chen JT, Chen YH, Tai MC, Chen CL et al. Protective effects of glucosamine on oxidative-stress and ischemia/reperfusion-induced retinal injury. Invest Ophthalmol Vis Sci 2015; 56: 1506-1516.

39. Linington C, Hohlfeld R. T-cell mediated autoimmunity: molecular interactions and therapeutic implications. J Autoimmun 1990; 3: 501-506.

40. Jeon JH, Suh HN, Kim MO, Ryu JM, Han HJ. Glucosamine-induced OGTactivation mediates glucose production through cleaved Notch1 and FoxO1, which coordinately contributed to the regulation of maintenance of self-renewal in mouse embryonic stem cells. Stem Cells Dev 2014; 23: 2067-2079.

41. Lima VV, Spitler K, Choi H, Webb RC, Tostes RC. O-GlcNAcylation and oxidation of proteins: is signalling in the cardiovascular system becoming sweeter? Clin Sci (Lond) 2012; 123: 473-486.

42. Singh LP, Cheng DW, Kowluru R, Levi E, Jiang Y. Hexosamine induction of oxidative stress, hypertrophy and laminin expression in renal mesangial cells: effect of the anti-oxidant $\alpha$-lipoic acid. Cell Biochem Funct 2007; 25: 537-550.

43. Speakman CM, Domke TC, Wongpaiboonwattana W, Sanders K, Mudaliar M, van Aalten DM et al. Elevated O-GIcNAc levels activate epigenetically repressed genes and delay mouse ESC differentiation without affecting naive to primed cell transition. Stem Cells 2014; 32 : 2605-2615.

44. Jang H, Kim TW, Yoon S, Choi SY, Kang TW, Kim SY et al. O-GIcNAc regulates pluripotency and reprogramming by directly acting on core components of the pluripotency network. Cell Stem Cell 2012; 11: 62-74.

45. Song $\mathrm{C}$, Song $\mathrm{C}$, Tong $\mathrm{F}$. Autophagy induction is a survival response against oxidative stress in bone marrow-derived mesenchymal stromal cells. Cytotherapy 2014; 16: 1361-1370.

46. Gutierrez-Uzquiza A, Arechederra M, Bragado P, Aguirre-Ghiso JA, Porras A. p38 $\alpha$ mediates cell survival in response to oxidative stress via induction of antioxidant genes: effect on the p70S6K pathway. J Biol Chem 2012; 287: 2632-2642.

47. Ferrer CM, Lynch TP, Sodi VL, Falcone JN, Schwab LP, Peacock DL et al. O-GlcNAcylation regulates cancer metabolism and survival stress signaling via regulation of the HIF-1 pathway. Mol Cell 2014; 54: 820-831.

48. Furuta E, Pai SK, Zhan R, Bandyopadhyay S, Watabe M, Mo YY et al. Fatty acid synthase gene is up-regulated by hypoxia via activation of Akt and sterol regulatory element binding protein-1. Cancer Res 2008; 68: 1003-1011.

49. Rankin EB, Rha J, Selak MA, Unger TL, Keith B, Liu $Q$ et al. Hypoxia-inducible factor 2 regulates hepatic lipid metabolism. Mol Cell Biol 2009; 29: 4527-4538.

50. Ben-David U, Gan QF, Golan-Lev T, Arora P, Yanuka O, Oren YS et al. Selective elimination of human pluripotent stem cells by an oleate synthesis inhibitor discovered in a highthroughput screen. Cell Stem Cell 2013; 12: 167-179.

51. Pebay A, Bonder CS, Pitson SM. Stem cell regulation by lysophospholipids. Prostaglandins Other Lipid Mediat 2007; 84: 83-97.

52. Foster DA. Phosphatidic acid and lipid-sensing by mTOR. Trends Endocrinol Metab 2013; 24: 272-278.

53. Gonzalez-Baro MR, Lewin TM, Coleman RA. Regulation of triglyceride metabolism. II. Function of mitochondrial GPAT1 in the regulation of triacylglycerol biosynthesis and insulin action. Am J Physiol Gastrointest Liv Physiol 2007; 292: G1195-G1199.

54. Coleman RA, Lee DP. Enzymes of triacylglycerol synthesis and their regulation. Prog Lipid Res 2004; 43: 134-176.

55. Sul HS, Wang D. Nutritional and hormonal regulation of enzymes in fat synthesis: studies of fatty acid synthase and mitochondrial glycerol-3-phosphate acyltransferase gene transcription. Annu Rev Nutr 1998; 18: 331-351.

56. Wendel AA, Cooper DE, Ilkayeva OR, Muoio DM, Coleman RA. Glycerol-3-phosphate acyltransferase (GPAT)-1, but not GPAT4, incorporates newly synthesized fatty acids into triacylglycerol and diminishes fatty acid oxidation. J Biol Chem 2013; 288: 27299-27306.

57. Ohba Y, Sakuragi T, Kage-Nakadai E, Tomioka NH, Kono N, Imae R et al. Mitochondria-type GPAT is required for mitochondrial fusion. EMBO J 2013; 32: 1265-1279.

58. Hammond LE, Albright CD, He L, Rusyn I, Watkins SM, Doughman SD et al. Increased oxidative stress is associated with balanced increases in hepatocyte apoptosis and proliferation in glycerol3-phosphate acyltransferase-1 deficient mice. Exp Mol Pathol 2007; 82: 210-219.

59. Liu J, Li T, Yang D, Ma R, Moran TH, Smith WW. Synphilin-1 alters metabolic homeostasis in a novel Drosophila obesity model. Int J Obes (Lond) 2012; 36: 1529-1536.

60. Solomon SS, Majumdar G, Martinez-Hernandez A, Raghow R. A critical role of Sp1 transcription factor in regulating gene expression in response to insulin and other hormones. Life Sci 2008; 83: 305-312.

61. Zhang X, Yang R, Jia Y, Cai D, Zhou B, Qu X et al. Hypermethylation of Sp1 binding site suppresses hypothalamic POMC in neonates and may contribute to metabolic disorders in adults: impact of maternal dietary CLAs. Diabetes 2014; 63: 1475-1487.

62. Chen S, Nagy PL, Zalkin H. Role of NRF-1 in bidirectional transcription of the human GPATAIRC purine biosynthesis locus. Nucleic Acids Res 1997; 25: 1809-1816.

63. Schaffer SW, Croft CB, Solodushko V. Cardioprotective effect of chronic hyperglycemia: effect on hypoxia-induced apoptosis and necrosis. Am J Physiol Heart Circ Physiol 2000; 278: H1948-H1954. 
64. Champattanachai V, Marchase RB, Chatham JC. Glucosamine protects neonatal cardiomyocytes from ischemia-reperfusion injury via increased protein-associated O-GlcNAc. Am J Physiol Cell Physiol 2007; 292: C178-C187.

65. Goldberg HJ, Scholey J, Fantus IG. Glucosamine activates the plasminogen activator inhibitor 1 gene promoter through Sp1 DNA binding sites in glomerular mesangial cells. Diabetes 2000; 49: 863-871.

66. Kudlow JE. Post-translational modification by O-GICNAc: another way to change protein function. J Cell Biochem 2006; 98: 1062-1075.

67. Dottori M, Leung J, Turnley AM, Pebay A. Lysophosphatidic acid inhibits neuronal differentiation of neural stem/progenitor cells derived from human embryonic stem cells. Stem Cells 2008; 26: 1146-1154

68. Ortlepp C, Steudel C, Heiderich C, Koch S, Jacobi A, Ryser M et al. Autotaxin is expressed in FLT3-ITD positive acute myeloid leukemia and hematopoietic stem cells and promotes cell migration and proliferation. Exp Hematol 2013; 41: 444-61.e4.

69. Costa M, Sourris K, Lim SM, Yu QC, Hirst CE, Parkington HC et al. Derivation of endothelial cells from human embryonic stem cells in fully defined medium enables identification of lysophosphatidic acid and platelet activating factor as regulators of eNOS localization. Stem Cell Res 2013; 10: 103-117.

70. Liu X, Hou J, Shi L, Chen J, Sang J, Hu S et al. Lysophosphatidic acid protects mesenchymal stem cells against ischemia-induced apoptosis in vivo. Stem Cells Dev 2009; 18: 947-954.

71. You JS, Frey JW, Hornberger TA. Mechanical stimulation induces mTOR signaling via an ERK-independent mechanism: implications for a direct activation of mTOR by phosphatidic acid. Plos One 2012; 7: e47258.

72. Mungamuri SK, Yang X, Thor AD, Somasundaram K. Survival signaling by Notch1: mammalian target of rapamycin (mTOR)-dependent inhibition of p53. Cancer Res 2006; 66: 4715-4724.

73. Kumar D, Shankar S, Srivastava RK. Rottlerin induces autophagy and apoptosis in prostate cancer stem cells via PI3K/Akt/mTOR signaling pathway. Cancer Lett 2014; 343: 179-189.
74. Zhou J, Wulfkuhle J, Zhang H, Gu P, Yang Y, Deng J et al. Activation of the PTEN/mTOR/ STAT3 pathway in breast cancer stem-like cells is required for viability and maintenance. Proc Natl Acad Sci USA 2007; 104: 16158-16163.

75. Marinov M, Ziogas A, Pardo OE, Tan LT, Dhillon T, Mauri FA et al. AKT/mTOR pathway activation and $\mathrm{BCL}-2$ family proteins modulate the sensitivity of human small cell lung cancer cells to RAD001. Clin Cancer Res 2009; 15: 1277-1287.

76. Morimoto A, Tomita S, Imanishi M, Shioi G, Kihira Y, Izawa-Ishizawa Y et al. Overexpressed $\mathrm{HIF-2} \alpha$ in endothelial cells promotes vascularization and improves random pattern skin flap survival. Plast Reconstr Surg Glob Open 2014; 2: e132.

77. Basu G, Downey H, Guo S, Israel A, Asmar A, Hargrave B et al. Prevention of distal flap necrosis in a rat random skin flap model by gene electro transfer delivering VEGF(165) plasmid. J Gene Med 2014; 16: 55-65.

78. de Carvalho EN, Ferreira LM, de Carvalho NA, Alba LE, Liebano RE. Viability of a random pattern dorsal skin flap, in diabetic rats. Acta Cir Bras 2005; 20: 225-228.

(c) Cell Death and Disease is an open-access journal published by Nature Publishing Group. This work is licensed under a Creative Commons Attribution 4.0 International License. The images or other third party material in this article are included in the article's Creative Commons license, unless indicated otherwise in the credit line; if the material is not included under the Creative Commons license, users will need to obtain permission from the license holder to reproduce the material. To view a copy of this license, visit http://creativecommons.org/licenses/by/4.0/

Supplementary Information accompanies this paper on Cell Death and Disease website (http://www.nature.com/cddis) 